\title{
Tracheostomy Tubes
}

\author{
Dean R Hess PhD RRT FAARC and Neila P Altobelli RRT
}

\author{
Introduction \\ Anatomy of the Tracheostomy Tube \\ Tracheostomy Tube Material \\ Tracheostomy Tube Dimensions \\ Extra Length Tracheostomy Tubes \\ Dual-Cannula Tracheostomy Tubes \\ Fenestrated Tracheostomy Tubes \\ Subglottic Suction Port \\ Tracheostomy Tube Cuffs \\ Stomal Maintenance Devices \\ Changing the Tracheostomy Tube \\ Decannulation \\ Tracheostomy Teams \\ Ward Versus ICU \\ Speaking With a Tracheostomy Tube \\ Spontaneously Breathing Patients \\ Mechanically Ventilated Patients \\ Summary
}

\begin{abstract}
Tracheostomy tubes are used to administer positive-pressure ventilation, to provide a patent airway, and to provide access to the lower respiratory tract for airway clearance. They are available in a variety of sizes and styles from several manufacturers. The dimensions of tracheostomy tubes are given by their inner diameter, outer diameter, length, and curvature. Differences in dimensions between tubes with the same inner diameter from different manufacturers are not commonly appreciated but may have important clinical implications. Tracheostomy tubes can be cuffed or uncuffed and may be fenestrated. Some tracheostomy tubes are designed with an inner cannula. It is important for clinicians caring for patients with a tracheostomy tube to appreciate the nuances of various tracheostomy tube designs and to select a tube that appropriately fits the patient. The optimal frequency of changing a chronic tracheostomy tube is controversial. Specialized teams may be useful in managing patients with a tracheostomy. Speech can be facilitated with a speaking valve in patients with a tracheostomy tube who are breathing spontaneously. In mechanically ventilated patients with a tracheostomy, a talking tracheostomy tube, a deflated cuff technique with a speaking valve, or a deflated cuff technique without a speaking valve can be used to facilitate speech. Key words: airway management; decannulation; fenestrated tracheostomy tube; inner cannula; speaking valve; tracheostomy button; tracheostomy team; tracheostomy tube. [Respir Care 2014;59(6):956-973.

(C) 2014 Daedalus Enterprises]
\end{abstract}

\section{Introduction}

Tracheostomy tubes are used to facilitate the administration of positive-pressure ventilation, to provide a patent airway in patients prone to upper airway obstruction, and to provide access to the lower respiratory tract for airway clearance. They are available in a variety of sizes and styles from several manufacturers. The inner diameter, outer diameter, and any other distinguishing characteristics (percutaneous, extra length, fenestrated) are marked on the 
flange of the tube as a guide to the clinician. Some features are relatively standard among typical tracheostomy tubes (Fig. 1). It is important for clinicians caring for patients with a tracheostomy tube to understand these differences and to use that understanding to select a tube that appropriately fits the patient. This paper describes characteristics of tracheostomy tubes used in adult patients, speaking with a tracheostomy, and issues related to management of the tracheostomy. It also covers issues related to speech in patients with a tracheostomy. This paper updates papers published previously in Respiratory CARE related to this topic. ${ }^{1,2}$

\section{Anatomy of the Tracheostomy Tube}

\section{Tracheostomy Tube Material}

Metal tubes are constructed of silver or stainless steel. They are not used commonly due to expense, rigid construction, and lack of a cuff and a $15-\mathrm{mm}$ connector to attach a ventilator. A smooth rounded-tip obturator passed through the lumen of the tracheostomy tube facilitates insertion of the tube by displacing rather than coring tissues; it is removed once the tube is in place. Metal is durable, inhibits bacteria growth, does not react with tissues, resists biofilm formation, is easy to clean, and can be sterilized with heat or steam.

The most commonly used tracheostomy tubes are made from polyvinyl chloride (PVC), silicone, or polyurethane. PVC softens at body temperature, conforming to patient anatomy and centering the tube in the trachea. Silicone is naturally soft and unaffected by temperature, resists colonization and biofilm buildup, and can be sterilized. Some tracheostomy tubes are packaged with a tracheal wedge, which facilitates removal of the ventilator circuit while minimizing the risk of dislodgement of the tracheostomy

The authors are affiliated with the Respiratory Care Department, Massachusetts General Hospital, Boston, Massachusetts. Dr Hess is also affiliated with the Department of Anesthesia, Harvard Medical School, Boston, Massachusetts.

Dr Hess presented this paper at the 52nd ResPiRAtory CARE Journal Conference, "Adult Artificial Airways and Airway Adjuncts" held June 14 and 15, 2013, in St Petersburg, Florida.

Dr Hess discloses relationships with Philips Respironics, Pari, Covidien, Maquet, Merck, and Bayer. Ms Altobelli has no relationships to disclose.

Drs Hess and Altobelli are co-first authors.

Correspondence: Dean Hess PhD RRT FAARC, Respiratory Care, Ellison 401, Massachusetts General Hospital, Boston, MA 02114. E-mail: dhess@ partners.org.

DOI: $10.4187 /$ respcare. 02920

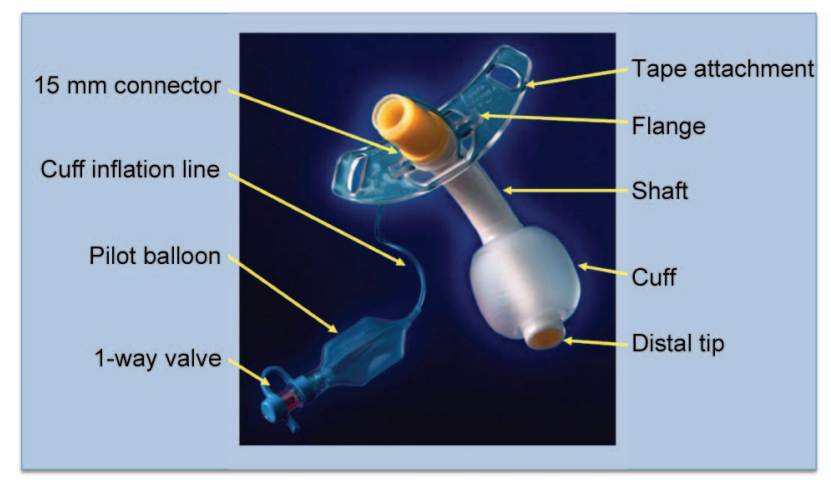

Fig. 1. Components of a standard tracheostomy tube.

Table 1. Jackson Tracheostomy Tube Size

\begin{tabular}{cccc}
\hline \hline \multirow{2}{*}{ Jackson Size } & \multicolumn{2}{c}{ Inner Diameter (mm) } & \multirow{2}{*}{$\begin{array}{c}\text { Outer } \\
\text { Diameter (mm) }\end{array}$} \\
\cline { 2 - 3 } & $\begin{array}{c}\text { With Inner } \\
\text { Cannula }\end{array}$ & $\begin{array}{c}\text { Without Inner } \\
\text { Cannula }\end{array}$ & \\
\hline 4 & 5.0 & 6.7 & 9.4 \\
6 & 6.4 & 8.1 & 10.8 \\
8 & 7.6 & 9.1 & 12.2 \\
10 & 8.9 & 10.7 & 13.8
\end{tabular}

The inner diameter of the outer cannula is for the narrowest portion of the shaft.

tube. Like the metal tube, an obturator facilitates insertion of the tube.

\section{Tracheostomy Tube Dimensions}

The dimensions of tracheostomy tubes are given by their inner diameter, outer diameter, length, and curvature. The sizes of some tubes are given by Jackson size, which was developed for metal tubes and refers to the length and taper of the outer diameter. These tubes have a gradual taper from the proximal to the distal tip. The Jackson sizing system is still used for most Shiley dual-cannula tracheostomy tubes (Table 1), but the International Organization for Standardization (ISO) method of sizing as determined by the inner diameter of the outer cannula at its smallest dimension is used for most other tubes. For dualcannula tubes, the diameter of the inner cannula is the functional inner diameter. The outer diameter is the largest diameter of the outer cannula.

Tracheostomy tubes that might at first seem similar may in fact be quite different in their dimensions (Fig. 2). When selecting a tracheostomy tube, the inner diameter, outer diameter, and length must be considered. If the inner diameter is too small, it will increase the resistance through the tube and make airway clearance more difficult. A smaller inner diameter may also result in a smaller outer diameter, which increases the cuff pressure required to 


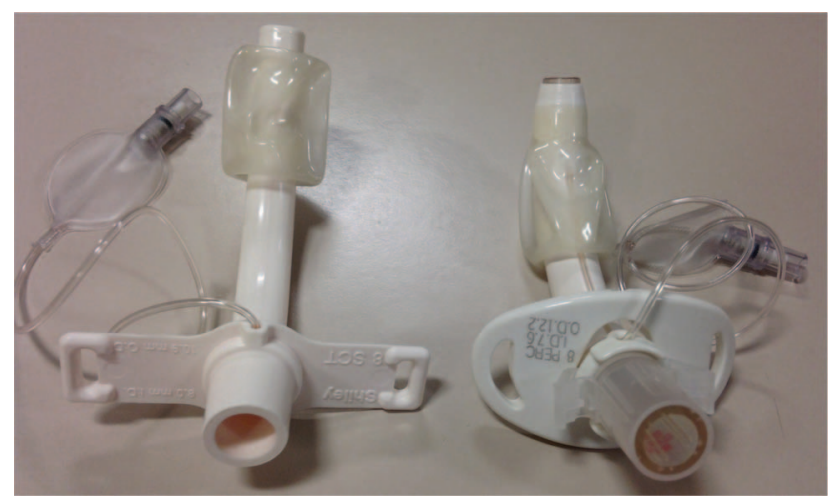

Fig. 2. Shiley single-cannula tube (left) and Shiley percutaneous tube (right). Both are size 8 tubes, but note the differences in size and style between them.

create a seal in the trachea. If the outer diameter is too large, the leak with the cuff deflated will be decreased, and this will affect the ability to use the upper airway with cuff deflation for speech. A tube with a larger outer diameter will also be more difficult to pass through the stoma. A 10 -mm outer diameter tube is usually appropriate for adult women, and an 11-mm outer diameter tube is usually appropriate for adult men as an initial tracheostomy tube size. A difference in tracheostomy tube length between tubes with the same inner diameter but from different manufacturers is not commonly appreciated (Table 2), and can have important clinical implications.

Tracheostomy tubes are angled or curved (Fig. 3), a feature that can be used to improve the fit of the tube in the trachea. The shape of the tube should conform as closely as possible to the anatomy of the airway. Because the trachea is essentially straight, the curved tube may not conform to the shape of the trachea, potentially allowing for compression of the membranous part of the trachea, while the tip may traumatize the anterior portion. Angled tracheostomy tubes have a curved portion and a straight portion. They enter the trachea at a less acute angle and may exert less pressure at the stoma. Because the portion of the tube that extends into the trachea is straight and conforms more closely to the natural anatomy of the airway, the angled tube may be better centered in the trachea and exert less pressure along the tracheal wall.

From in vivo and in vitro dimensions, Mallick et al ${ }^{3}$ reported that standard length tracheostomy tubes are too short for the typical critically ill patient. They recommend that both the stomal and intratracheal lengths be made longer by $\sim 1 \mathrm{~cm}$ and that tubes should be redesigned to an angle of $110-120^{\circ}$ to allow optimal tracheal placement.

Low-profile tracheostomy tubes have a small discrete flange and are used in patients with a laryngectomy or sleep apnea. Percutaneous tracheostomy tubes have a tapered distal tip, a low-profile cuff designed to reduce in- sertion force, and an inverted cuff shoulder for easier insertion.

\section{Extra Length Tracheostomy Tubes}

If the tracheostomy tube is too short, the distal end can obstruct against the posterior tracheal wall (Fig. 4 and Table 3). This can be remedied by using a larger tube, an angled tube, a tube with a flexible shaft, or a tube with extra length. Extra length tubes are constructed with extra proximal length (horizontal extra length) or with extra distal length (vertical extra length).

Extra proximal length facilitates tracheostomy tube placement in patients with a large neck (eg, obese patients). Extra distal length facilitates placement in patients with tracheomalacia or tracheal anomalies. Care must be taken to avoid inappropriate use of these tubes because they may induce distal obstruction of the tube. ${ }^{5}$

Several tube designs have a spiral wire-reinforced flexible design. These tubes are not compatible with lasers, electrosurgical devices, or magnetic resonance imaging. Some have a moveable flange designed to allow adjustments to better fit the tube to the patient's unique anatomy (Table 4). Because the locking mechanism on the flange tends to deteriorate over time, these tubes should be considered a temporary solution. For long-term use, the adjustable flange tube should be replaced with a tube that has a fixed flange. Custom-constructed tubes are available from several manufacturers to meet this need.

Tibballs et $\mathrm{al}^{6}$ found that the Portex Bivona adjustable length tracheostomy tube, which assumes a curve on insertion, has a tendency to straighten itself in situ. The straightening force was a maximal of 0.21 newtons when a tube was bent $90^{\circ}$. They reported several clinical disadvantages of these tubes: tracheal ulceration, distortion of the soft tracheal tissue, and airway obstruction when the tip embedded into the tracheal wall.

Tracheostomy tube malposition is a potentially serious issue. Schmidt et $\mathrm{al}^{7}$ performed a retrospective study on consecutive subjects with a tracheostomy who had been admitted to an acute care unit specializing in weaning from mechanical ventilation. Bronchoscopy reports were reviewed for evidence of tracheostomy tube malposition, defined as $>50 \%$ occlusion of the lumen by tissue. Malpositioned tracheostomy tubes were identified in 40 of 403 subjects (10\%). Malposition was associated with prolonged mechanical ventilation post-tracheostomy ( 25 vs $15 \mathrm{~d}$ ). The most common malposition resulted in the posterior tracheal wall occluding the distal tip of the tube. Malpositioned tracheostomy tubes were changed to a better fitting tube in $80 \%$ of cases. In $35 \%$ of cases, PEEP was used to dilate the trachea, thus reducing the degree of distal tip occlusion. These data suggest that there should be a high index of suspicion for tracheostomy tube malposition when 
Tracheostomy Tubes

Table 2. Dimensions of Portex Flex DIC, Shiley SCT, and Bivona Mid-Range Aire-Cuf Tracheostomy Tubes

\begin{tabular}{|c|c|c|c|c|c|c|c|c|}
\hline \multicolumn{3}{|c|}{ Portex Flex D.I.C. (mm) } & \multicolumn{3}{|c|}{ Shiley SCT (mm) } & \multicolumn{3}{|c|}{ Bivona Mid-Range Aire-Cuf (mm) } \\
\hline ID & OD & Length & ID & OD & Length & ID & OD & Length \\
\hline 6.0 & 8.2 & 64 & 6.0 & 8.3 & 67 & 6.0 & 8.8 & 67 \\
\hline 7.0 & 9.6 & 70 & 7.0 & 9.6 & 80 & 7.0 & 10.0 & 80 \\
\hline 8.0 & 10.9 & 74 & 8.0 & 10.9 & 89 & 8.0 & 11.0 & 89 \\
\hline 9.0 & 12.3 & 80 & 9.0 & 12.1 & 99 & 9.0 & 12.3 & 99 \\
\hline 10.0 & 13.7 & 80 & 10.0 & 13.3 & 105 & 9.5 & 13.3 & 105 \\
\hline $\begin{array}{l}\text { The prin } \\
\text { D.I.C. = } \\
\text { SCT }=\text { s } \\
\text { ID }=\text { inn } \\
\text { OD = ou }\end{array}$ & $\begin{array}{l}\text { betwe } \\
\text { ner cann } \\
\text { tube }\end{array}$ & $s$ their leng & $x$ tube $c$ & with an & nula, which & ner dia & & \\
\hline
\end{tabular}

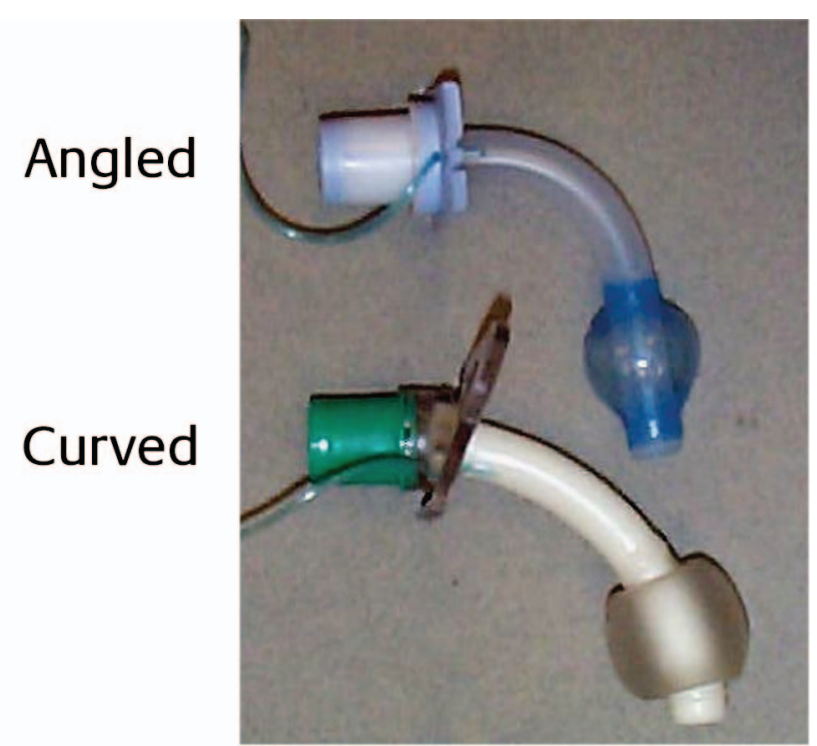

Fig. 3. Angled and curved tracheostomy tubes.

patients demonstrate unanticipated difficulty in being liberated from mechanical ventilation following tracheostomy.

\section{Dual-Cannula Tracheostomy Tubes}

Some tracheostomy tubes are used with an inner cannula, and these are called dual-cannula tracheostomy tubes. In some cases, the $15-\mathrm{mm}$ attachment is on the inner cannula, and a ventilator cannot be attached unless the inner cannula is in place. The use of an inner cannula allows it to be cleaned or replaced at regular intervals without removing the tracheostomy tube from its stoma. It has been hypothesized that this may reduce biofilm formation and the incidence of ventilator-associated pneumonia. However, data are lacking to support this hypothesis, and the results of one study suggested that changing the inner
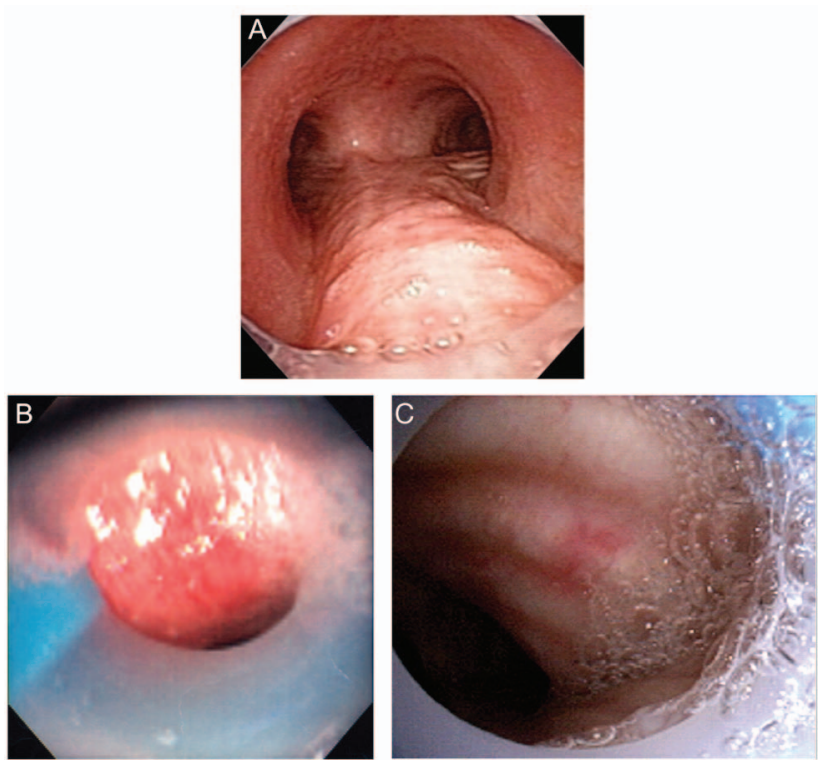

Fig. 4. A: Endoscopic view showing a correctly positioned tracheostomy tube. B and C: malpositioned tracheostomy tubes. From Reference 4.

cannula on a regular basis in the critical care unit is unnecessary. ${ }^{8}$ The inner cannula can be removed to restore a patent airway if the tube occludes, which may be an advantage for long-term use outside an acute care facility. If a fenestrated tracheostomy tube is used, the inner cannula occludes the fenestrations unless there are also fenestrations on the inner cannula.

One potential issue with the use of an inner cannula is that it reduces the inner diameter of the tracheostomy tube (Table 5); thus, the imposed work of breathing for a spontaneously breathing patient is increased. This was investigated by Cowan et $\mathrm{al}^{9}$ in an in vitro study, in which they reported a significant decrease in imposed work of breathing when the inner cannula was removed. They concluded that increasing the inner diameter of the tracheostomy tube 
Table 3. Dimensions of Shiley XLT Extra-Length Tracheostomy Tubes

\begin{tabular}{ccc}
\hline \hline $\begin{array}{c}\text { Inner Diameter } \\
(\mathrm{mm})\end{array}$ & $\begin{array}{c}\text { Outer Diameter } \\
(\mathrm{mm})\end{array}$ & $\begin{array}{c}\text { Length } \\
(\mathrm{mm})\end{array}$ \\
\hline Shiley XLT proximal extension tracheostomy tubes \\
5.0 & 9.6 & $90(20 \mathrm{~mm}$ proximal, \\
& & $37 \mathrm{~mm}$ radial, $33 \mathrm{~mm}$ distal $)$ \\
6.0 & 11.0 & $95(23 \mathrm{~mm}$ proximal, \\
7.0 & 12.3 & $38 \mathrm{~mm}$ radial, 34 mm distal $)$ \\
& $100(27 \mathrm{~mm}$ proximal, \\
8.0 & 13.3 & $39 \mathrm{~mm}$ radial, 34 mm distal $)$ \\
& & $105(30 \mathrm{~mm}$ proximal, \\
& & $40 \mathrm{~mm}$ radial, 35 mm distal $)$
\end{tabular}

Shiley XLT distal extension tracheostomy tubes

$\begin{array}{ccc}5.0 & 9.6 & 90(5 \mathrm{~mm} \text { proximal, } \\ & & 37 \mathrm{~mm} \text { radial, } 48 \mathrm{~mm} \text { distal }) \\ 6.0 & 11.0 & 95(8 \mathrm{~mm} \text { proximal, } \\ & & 38 \mathrm{~mm} \text { radial, } 49 \mathrm{~mm} \text { distal }) \\ 7.0 & 12.3 & 100(12 \mathrm{~mm} \text { proximal, } \\ & & 39 \mathrm{~mm} \text { radial, } 49 \mathrm{~mm} \text { distal }) \\ 8.0 & 13.3 & 405(15 \mathrm{~mm} \text { proximal, } \\ & & 40 \mathrm{~mm} \text { radial, } 50 \mathrm{~mm} \text { distal })\end{array}$

Table 4. Dimensions of Flexible Tracheostomy Tubes With an Adjustable Flange

\begin{tabular}{ccc}
\hline \hline $\begin{array}{c}\text { Inner Diameter } \\
(\mathrm{mm})\end{array}$ & $\begin{array}{c}\text { Outer Diameter } \\
(\mathrm{mm})\end{array}$ & $\begin{array}{c}\text { Length } \\
(\mathrm{mm})\end{array}$ \\
\hline
\end{tabular}

Rusch Ultra TracheoFlex with adjustable flange*

$\begin{array}{rrr}7.0 & 10.4 & 63 \\ 8.0 & 11.4 & 88 \\ 9.0 & 12.4 & 117 \\ 10.0 & 13.4 & 117 \\ 11.0 & 14.4 & 116\end{array}$

Bivona Mid-Range Aire-Cuf Adjustable Neck Flange

$\begin{array}{rrr}6.0 & 9.2 & 110 \\ 7.0 & 10.6 & 120 \\ 8.0 & 11.7 & 130 \\ 9.0 & 12.9 & 140\end{array}$

* Available also with additional extratracheal length $(30$ or $40 \mathrm{~mm}$ ) or additional intratracheal length $(40 \mathrm{~mm})$.

by removing the inner cannula might be beneficial in spontaneously breathing patients.

\section{Fenestrated Tracheostomy Tubes}

The fenestrated tracheostomy tube (Fig. 5) is similar in construction to standard tracheostomy tubes with the addition of an opening in the posterior portion of the tube above the cuff. With the inner cannula removed, the cuff
Table 5. Comparison of Shiley SCT and DCT Dimensions

\begin{tabular}{|c|c|c|c|c|}
\hline \multicolumn{2}{|c|}{ Shiley SCT (mm) } & \multicolumn{3}{|c|}{ Shiley DCT (same as Jackson) } \\
\hline $\begin{array}{c}\text { Inner } \\
\text { Diameter }\end{array}$ & $\begin{array}{c}\text { Outer } \\
\text { Diameter }\end{array}$ & Size & $\begin{array}{l}\text { Inner Diameter } \\
\qquad(\mathrm{mm})^{*}\end{array}$ & $\begin{array}{l}\text { Outer Diameter } \\
(\mathrm{mm})\end{array}$ \\
\hline 6.0 & 8.3 & 6 & 6.4 (8.1 mm without IC) & 10.8 \\
\hline 8.0 & 10.9 & 8 & 7.6 (9.1 mm without IC) & 12.2 \\
\hline 10.0 & 13.3 & 10 & 8.9 (10.7 mm without IC) & 13.8 \\
\hline \multicolumn{5}{|c|}{$\begin{array}{l}\text { * The inner diameter of the outer cannula is for the narrowest portion of the shaft. } \\
\text { SCT = single-cannula tube } \\
\text { DCT = double-cannula tube } \\
\text { IC = inner cannula }\end{array}$} \\
\hline
\end{tabular}

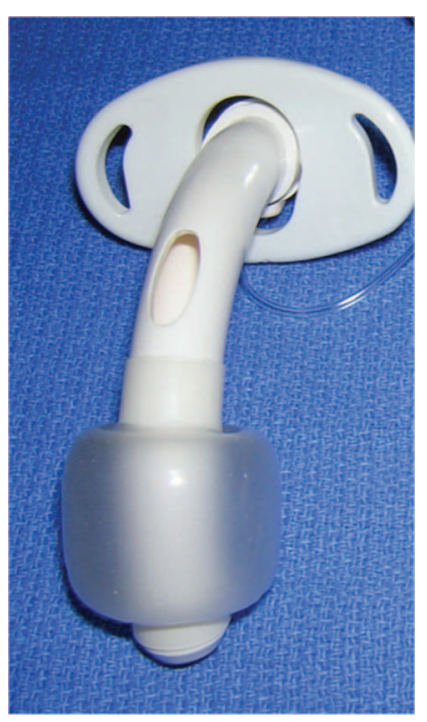

Fig. 5. Fenestrated tracheostomy tube.

deflated, and the normal air passage inlet of the tube occluded, the patient can inhale and exhale through the fenestration and around the tube. This allows for assessment of the patient's ability to breathe through the normal oral/nasal route (preparing the patient for decannulation) and permits air to pass by the vocal cords (allowing phonation). Supplemental oxygen administration to the upper airway (eg, nasal cannula) may be necessary if the tube is capped. The cuff must be completely deflated by evacuating all of the air before the tube is capped. The decannulation cap is then put in place to allow the patient to breathe through the fenestrations and around the tube.

Fenestrated tracheostomy tubes often fit poorly and thus do not work as intended. The standard commercially available tubes can significantly increase flow resistance through the upper airway if the fenestrations are not properly positioned. The risk of this complication may be decreased if a tube is used with several fenestrations rather than a single fenestration. Moreover, custom-fenestrated tubes can be ordered from several manufacturers. Even with these 


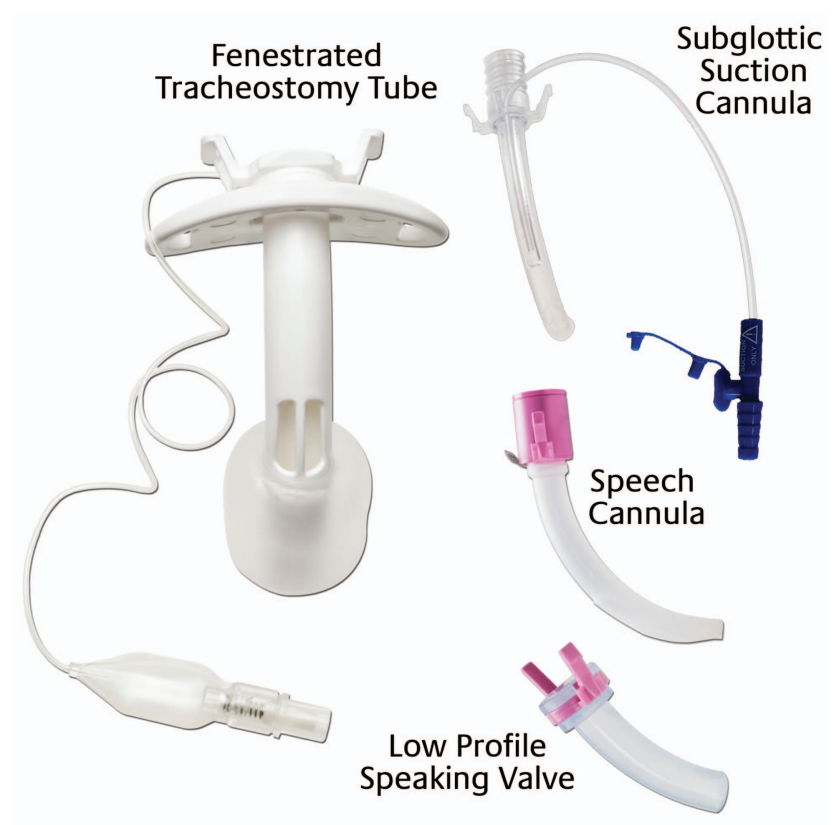

Fig. 6. Blom tracheostomy tube. Courtesy Pulmodyne.

measures, the fenestrations may cause the formation of granulation tissue, resulting in airway compromise. ${ }^{10}$ Proper position of the fenestrations in the airway should be inspected regularly.

Using an in vitro tracheal model, Hussey and Bishop ${ }^{11}$ reported that the effort required for gas flow across the native airway in the absence of a fenestration might be substantial. Carter et al $^{12}$ reported that the inner cannula increased the resistive work of breathing by an average factor of 2.2. The extra work of breathing imposed exceeded the normal total work of breathing.

\section{Subglottic Suction Port}

Tracheostomy tubes that provide a suction port above the cuff are available. One such design is the Blom tracheostomy tube (Fig. 6). The subglottic suctioning cannula is located on the exterior surface of the cannula as a separate lumen, which can be connected to intermittent or continuous suction, and is intended for the evacuation of secretions situated above the tracheostomy tube cuff. Although subglottic suction has been shown to reduce the risk of ventilator-associated pneumonia when endotracheal tubes are used, ${ }^{13}$ to our knowledge, no such data are available for tracheostomy tubes.

\section{Tracheostomy Tube Cuffs}

Tracheostomy tubes can be cuffed or uncuffed. Uncuffed tubes allow airway clearance but provide no protection from aspiration. Cuffed tracheostomy tubes allow secretion clearance and offer some protection from aspiration, and positive-pressure ventilation can be more effectively applied when the cuff is inflated. Specific types of cuffs used on tracheostomy tubes include high-volume low-pressure cuffs, tight-to-shaft cuffs (low-volume highpressure), and foam cuffs. High-volume low-pressure cuffs are most commonly used.

Tracheal capillary perfusion pressure is normally 25$35 \mathrm{~mm} \mathrm{Hg}$. Because the pressure transmitted from the cuff to the tracheal wall is usually less than the pressure in the cuff, it is generally agreed that $30 \mathrm{~cm} \mathrm{H}_{2} \mathrm{O}(22 \mathrm{~mm} \mathrm{Hg})$ is the maximal acceptable intracuff pressure. If the cuff pressure is too low, silent aspiration is more likely. Therefore, it is recommended that cuff pressure be maintained at $20-30 \mathrm{~cm} \mathrm{H}_{2} \mathrm{O}(15-22 \mathrm{~mm} \mathrm{Hg})$ to minimize the risks for both tracheal wall injury and aspiration. A leak around the cuff is assessed by auscultation over the suprasternal notch or the lateral neck. Techniques such as the minimal occlusion pressure or minimal leak technique are not recommended. In particular, the minimal leak technique is not recommended as it may increase the risk of silent aspiration. Intracuff pressure should be monitored and recorded regularly (eg, once per shift) and more often if the tube is changed, if its position changes, if the volume of air in the cuff is changed, or if a leak occurs. In addition to the increased potential for airway injury with higher cuff pressures, the swallowing reflex is more difficult to elicit with increasing cuff pressure, and when activated, the resulting motor swallowing activity and efficiency in elevating the larynx are depressed. ${ }^{14}$

A common cause of high cuff pressure is that the tube is too small, resulting in overfilling of the cuff to achieve a seal in the trachea. Another common cause of high cuff pressure is malposition of the tube (eg, cuff inflated in the stoma). Other causes of high cuff pressure include overfilling of the cuff, tracheal dilation, and use of a lowvolume high-pressure cuff.

The tight-to-shaft cuff minimizes air-flow obstruction around the outside of the tube when the cuff is deflated. It is a low-volume high-pressure cuff intended for patients requiring intermittent cuff inflation. When the cuff is deflated, speech and upper airway use are facilitated. The cuff is constructed of silicone. It should be inflated with sterile water because otherwise the cuff will automatically deflate over time due to gas permeability. A single-lumen tube with a tight-to-shaft cuff might be useful to minimize resistance when breathing through the tube and when breathing around the tube with the cuff deflated. ${ }^{15}$

A foam cuff consists of a large-diameter high-residual volume cuff composed of polyurethane foam covered by a silicone sheath. The foam cuff was designed to address the issues of high lateral tracheal wall pressures that lead to complications such as tracheal necrosis and stenosis. Before insertion, a syringe attached to the pilot port evacuates 
air in the cuff. Once the tube is in place, the syringe is removed to allow the cuff to re-expand against the tracheal wall. The pilot tube remains open to the atmosphere, so the intracuff pressure is at ambient levels. The open pilot port also permits compression and expansion of the cuff during the ventilatory cycle. The degree of expansion of the foam is a determining factor of the degree of tracheal wall pressure. As the foam further expands, lateral tracheal wall pressure increases. When used properly, this pressure does not exceed $20 \mathrm{~mm} \mathrm{Hg}\left(27 \mathrm{~cm} \mathrm{H}_{2} \mathrm{O}\right)$. The proper size is important to maintain a seal and the benefit from the pressure-limiting advantages of the foam-filled cuff. If the tube is too small, the foam will inflate to its unrestricted size and not touch the tracheal wall, causing loss of ventilation and loss of protection against aspiration. If a leak occurs during positive-pressure ventilation with the foam cuff, it can be attached to the ventilator circuit so that cuff pressure approximates airway pressure. If the tube is too large, the foam is unable to expand properly to provide the desired cushion, with increased pressure against the tracheal wall. The manufacturer recommends periodic cuff deflation to determine the integrity of the cuff and to prevent the silicone cuff from adhering to the tracheal mucosa. Despite the availability of this cuff type for many years, it is not commonly used. Its use is often reserved for patients who have already developed tracheal injury related to the cuff.

Beard and Monaco ${ }^{16}$ reported that the presence of a cuff, either inflated or deflated, might increase the amount of ventilatory work required of the patient. They recommended that uncuffed tubes be used to decrease patient work of breathing when the tube is capped and to improve patient comfort during the process of decannulation. If the cuff is deflated or an uncuffed tube is used, the patient must be observed carefully for potential aspiration of upper airway secretions or oral fluids. Hernandez et al ${ }^{17}$ randomized critically ill tracheostomized patients to have the tracheal cuff deflated or not during spontaneous breathing trials. They found that deflating the tracheostomy tube cuff shortened weaning time, reduced respiratory infections, and improved swallowing.

\section{Stomal Maintenance Devices}

Several approaches can be used for stomal maintenance in patients who cannot be decannulated. One of the easiest approaches is to use a small cuffless tracheostomy tube (eg, size 4 cuffless). Another approach is to use a tracheostomy button (Fig. 7). This device consists of a hollow outer cannula and a solid inner cannula. It fits from the skin to just inside the anterior wall of the trachea. With the solid inner cannula in place, the patient breathes through the upper airway. When the inner cannula is removed, the patient can breathe through the button, and a suction cath-

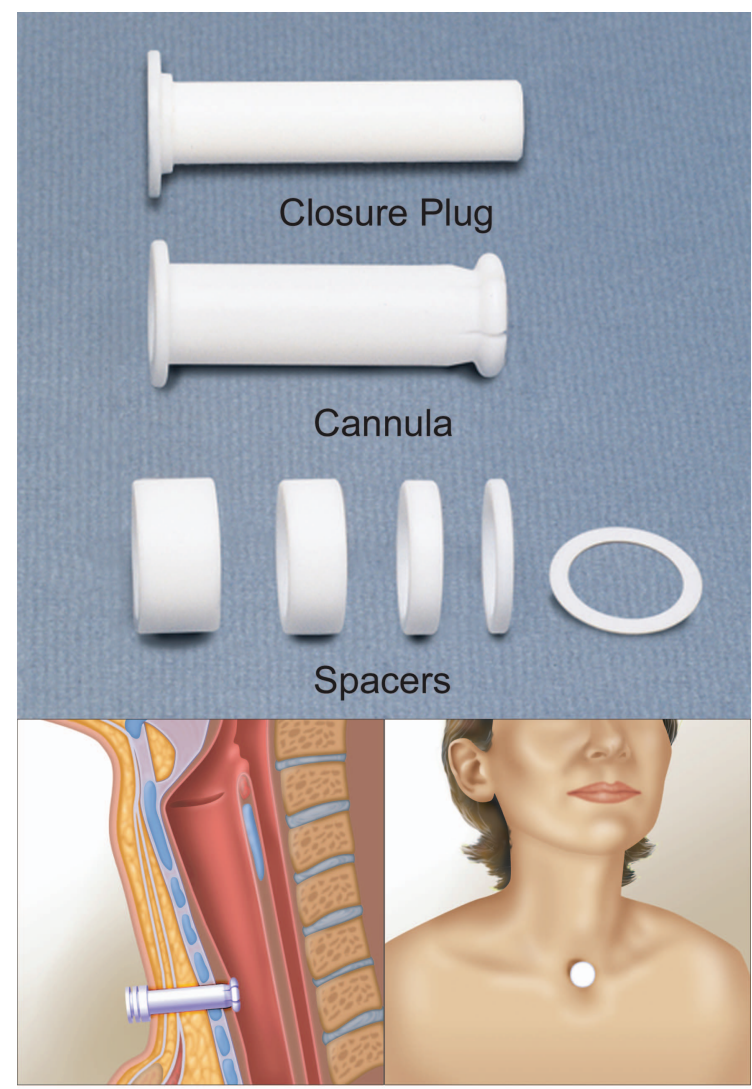

Fig. 7. Olympic Trach-Button. Courtesy Natus Medical.
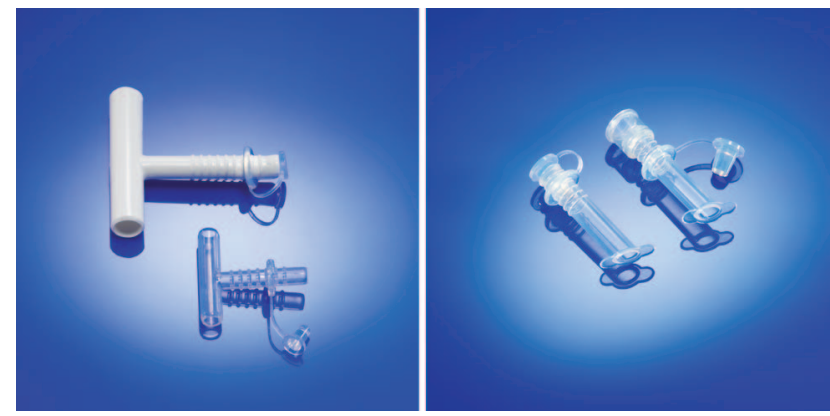

Fig. 8. Montgomery Safe-T-Tube (left) and long-term cannula (right). Courtesy Boston Medical Products.

eter can be passed through the button to aid airway clearance. Since a tracheostomy button does not extend into the trachea and does not have a cuff, its use is limited when there is a risk of aspiration or during positive-pressure ventilation. Other devices used for stomal maintenance include the Montgomery Safe-T-Tube and the Montgomery long-term cannula (Fig. 8).

\section{Changing the Tracheostomy Tube}

The tracheostomy tube may be changed to another one for a number of reasons: to reduce the size of the tube, to 


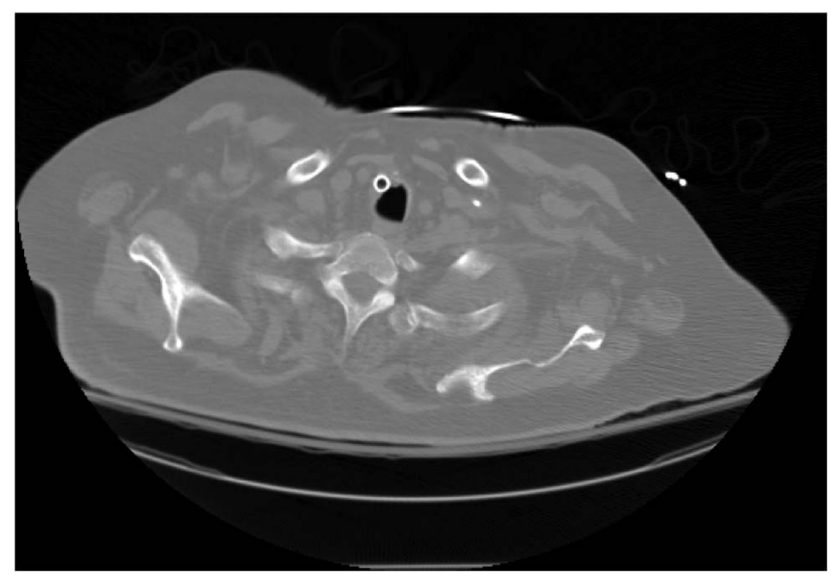

Fig. 9. Computed tomography radiograph showing tracheostomy tube placed into a false track.

change the length of the tube if it is malpositioned, because it is obstructed with secretions, because it is broken (eg, cuff leak), to change the type of tube, or as a routine change with a chronic tracheostomy. ${ }^{4}$ The first tracheostomy tube change carries some risk and should be performed by a skilled operator in a safe environment; this will often be supervised by the clinical service that initially placed the tube. The risk associated with changing the tracheostomy tube diminishes over time as the stoma matures. When the stoma is mature and the tube has been replaced previously without incident, the procedure can be safely performed by respiratory therapists (RTs).

The process of changing a tracheostomy tube is usually straightforward. ${ }^{4}$ It is advisable to have 2 people present. Prior to removing the old tube, all components of the new tracheostomy tube should be checked for integrity, the obturator should be placed into the tube, and the cuff should be inflated to check for leaks and then deflated prior to insertion. Water-soluble lubricant is placed on the tube. The patient is placed either supine or semirecumbent, with the neck extended. If present, retaining sutures are removed, the tube is gently withdrawn, the new tracheostomy tube inserted, and the obturator is removed. Removal of a tube through a tight stoma with a bulky cuff can be facilitated using lidocaine jelly or water-soluble lubricant inserted around the stoma/tube interface. Once the new tube is in place, its position in the trachea is confirmed by air flow through the tube if the patient is breathing spontaneously or the presence of bilateral breath sounds during positive-pressure ventilation. Of concern is that the tube may be placed into a false track outside of the trachea. The presence of carbon dioxide in the exhaled gas confirms that the tube is in the trachea. Bronchoscopy and chest radiography (Fig. 9) can also be used to confirm tube placement.

The new tracheostomy tube can usually be inserted using the obturator packaged with the tube. If difficulty is

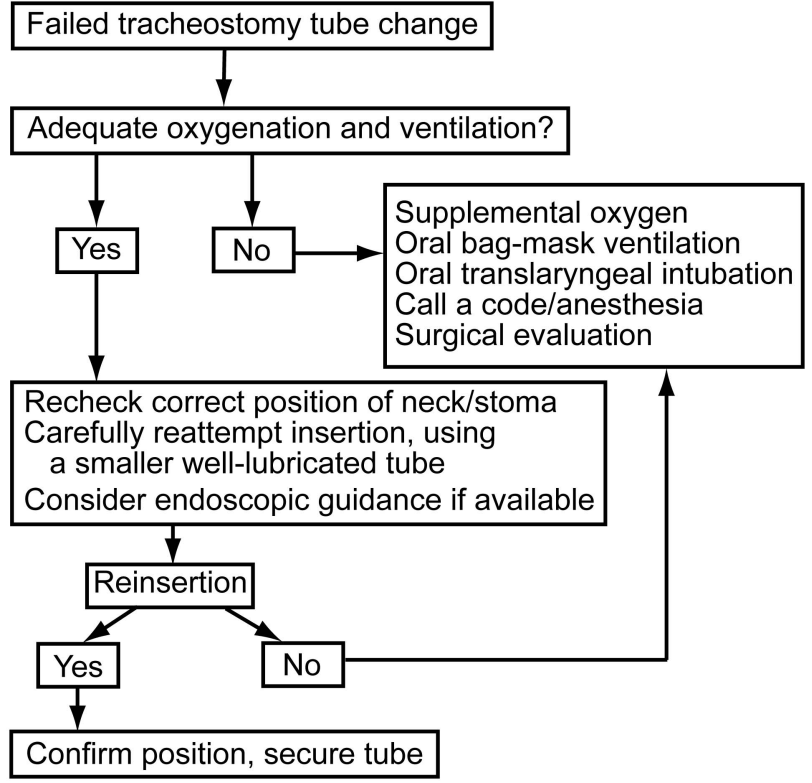

Fig. 10. Algorithm to manage failure to replace a tracheostomy tube during a routine change. From Reference 4.

anticipated during a tracheostomy tube change, a tube exchanger or suction catheter ${ }^{18}$ can be used to facilitate this procedure. The tube exchanger is passed through the tube into the trachea. The tube is then withdrawn while keeping the tube changer in place, and the new tube is passed over the tube changer into the trachea. If difficulty changing the tube is anticipated, it is advisable that a clinician skilled in endotracheal intubation is present or that the tube is changed in the operating room. Generally, the tracheostomy tube should be changed in a clinical unit (ICU, ward, clinic). Changing the tracheostomy tube in the patient's home is not recommended because monitoring is suboptimal and because the ability to adequately respond to loss of the airway is inadequate.

Bleeding can occur during a tracheostomy tube change, particularly if the patient is anticoagulated or if there is granulation tissue at the stoma. Of greatest concern is the inability to insert the new tube. It is advisable to have a backup tube of smaller size available in case this should occur. An algorithm to manage failure to replace a tracheostomy tube during a routine change is shown in Figure 10.

It is commonly recommended that the initial tracheostomy tube change should occur between days 7 and 14 post-insertion. Safely changing the tube before day 7 could lead to earlier use of a speaking valve and earlier oral intake. Fisher et al ${ }^{19}$ found that the first change of a tracheostomy tube before day 7 was associated with an earlier tolerance of a speaking valve and earlier oral feeding and was not associated with important complications. Even if the tube is not changed, the results of this study suggest 


\section{Tracheostomy Tubes}
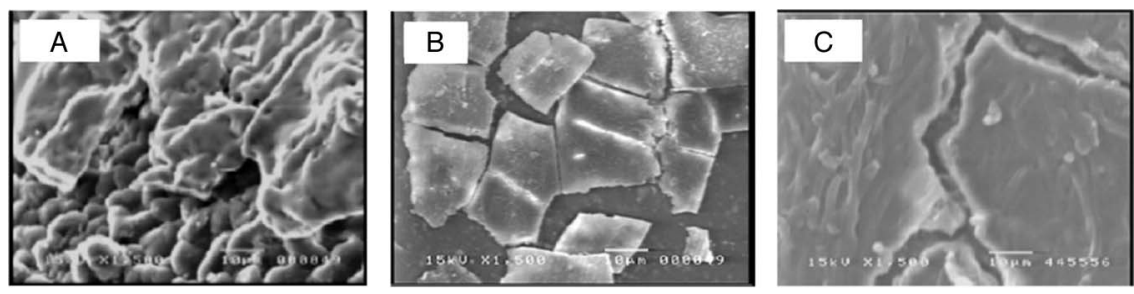

Fig. 11. A: Scanning electron microscopy image of Bivona TTS silicone tube after 3 months of use. B: Scanning electron microscopy images of Shiley polyvinyl chloride tracheostomy tube after 3 months of use. C: Scanning electron microscopy images of Tracoe Twist polyurethane tracheostomy tube after $30 \mathrm{~d}$ of use. From Reference 23 with permission.

that retention sutures might be removed before day 7 , which could reduce the risk of skin breakdown at the suture site.

Tabaee et $\mathrm{al}^{20}$ conducted a survey of chief residents in accredited otolaryngology training programs to determine the management strategies, rationale, and complications associated with tracheostomy tube changes. The first tube change was performed after a mean of $5 \mathrm{~d}$ (range of 3-7 d) after placement and was performed in a variety of locations, including the ICU (88\%), a step-down unit (80\%), and a regular floor (78\%). The most frequently reported rationales for performing routine tracheostomy changes were examination of the stoma $(46 \%)$, prevention of stomal infection (46\%), and confirmation of stability for transport to a less monitored setting (41\%). Of interest, $42 \%$ of respondents reported knowing of a loss of airway, and $15 \%$ reported knowing of a death as a result of the first tube change at their institution. A higher incidence of airway loss was reported when the first tube change was performed on the floor rather than in the ICU.

The need for routine tracheostomy tube changes is somewhat unclear. In an observational study, Yaremchuk ${ }^{21}$ reported fewer complications due to granulation tissue after implementation of a policy requiring tracheostomy tubes to be changed every 2 weeks. Manufacturers include recommendations for routine changes of tracheostomy tubes in their package inserts. ${ }^{4}$ Shiley recommends changing their PVC tracheostomy tubes every 29 d. The Portex Blue Line package insert recommends $30 \mathrm{~d}$ as the maximal recommended period of use. The Portex Bivona tube package insert recommends it be used for up to $29 \mathrm{~d}$. Many manufacturers recommend that a tube with an inner cannula should not be used for $>30 \mathrm{~d}$.

Several studies have reported material breakdown of tracheostomy tubes over time. Björling et al ${ }^{22}$ compared the duration of use of silicone, PVC, and polyurethane tubes. All tubes were exposed in the trachea for $30 \mathrm{~d}$ before being analyzed by scanning electron microscopy and attenuated total reflectance Fourier transform infrared spectroscopy. Surface changes were noted in 18 of the 19 tubes. Backman et $\mathrm{al}^{23}$ evaluated the long-term material wear of tracheostomy tubes made of silicone, PVC, and

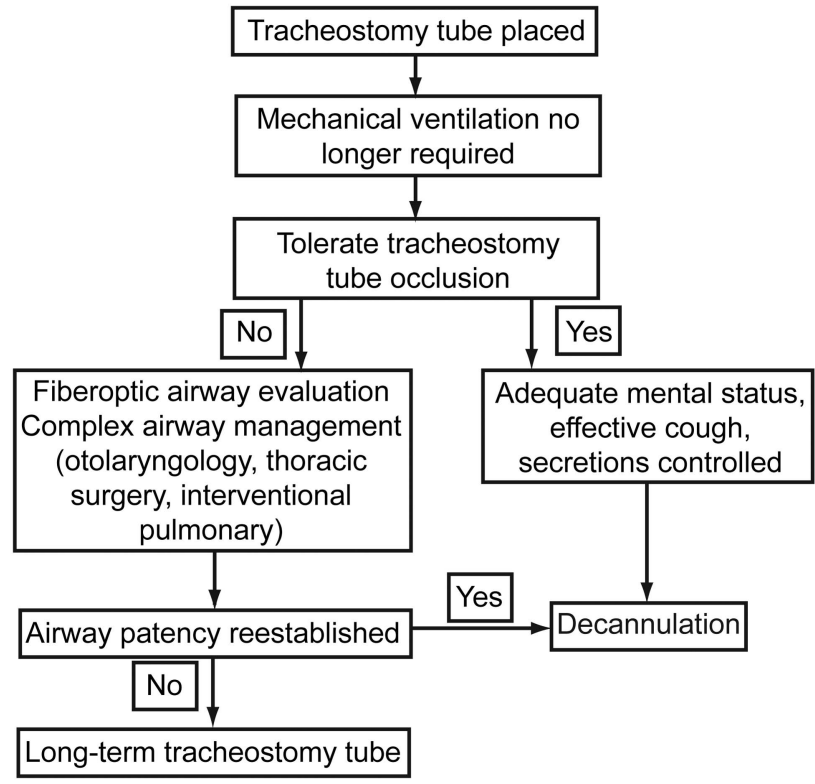

Fig. 12. Decannulation assessment. From Reference 26.

polyurethane after 3 and 6 months of clinical use. All tubes revealed severe surface changes (Fig. 11).

\section{Decannulation}

There is a relative lack of evidence to inform when a tracheostomy tube should be removed. It has been proposed that decannulation be considered in patients once mechanical ventilation is no longer needed, upper airway obstruction is resolved, airway secretions are controlled, and swallowing has been evaluated. ${ }^{24-26}$ Long-term care of the patient with a tracheostomy can be fragmented, such that the clinicians faced with the decision to decannulate are often not the same physicians who inserted the tracheostomy. O'Connor and White ${ }^{26}$ have suggested an algorithm for decannulation assessment (Fig. 12).

Stelfox et $\mathrm{al}^{27}$ conducted a cross-sectional survey of physicians and RTs with expertise in the management of tracheostomized patients at 118 medical centers to char- 

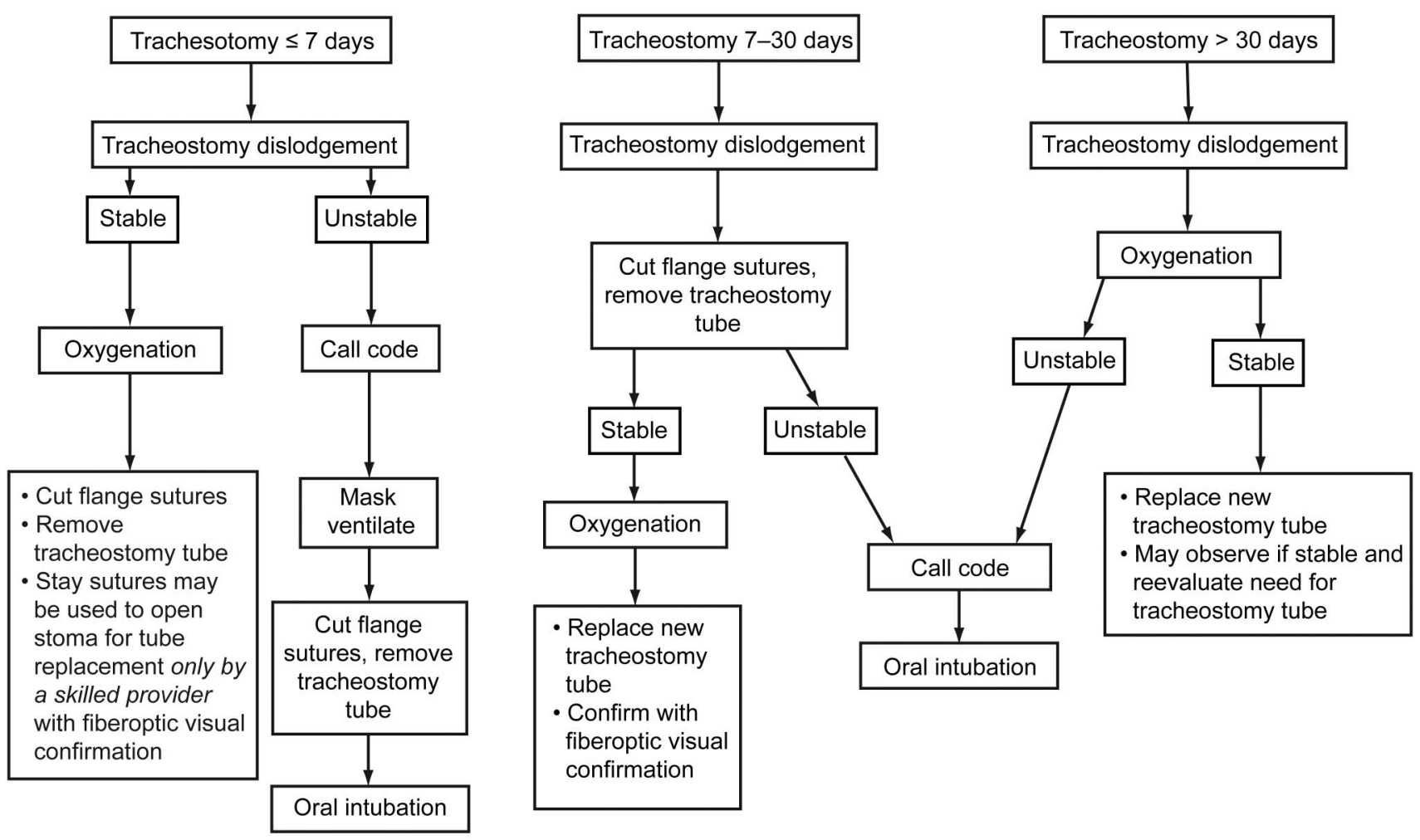

Fig. 13. Algorithm for managing unplanned tracheostomy tube dislodgement. From Reference 26.

acterize contemporary opinions about tracheostomy decannulation practice and to define factors that influence these practices. Clinicians rated patient level of consciousness, ability to tolerate tracheostomy tube capping, cough effectiveness, and secretions as the most important factors in the decision to decannulate. Clinicians who worked in chronic care facilities were less likely to recommend decannulation than clinicians who worked in weaning, rehabilitation, or acute care facilities. Patients were most likely to be considered for decannulation if they were alert and interactive (odds ratio [OR] 4.76), had a strong cough (OR 3.84), had scant thin secretions (OR 2.23), and required minimal supplemental oxygen (OR 2.04). In a secondary analysis of these data, Stelfox et $\mathrm{al}^{28}$ investigated whether similar decisions are made by RTs and physicians related to decannulation recommendations. RTs placed greater emphasis on ability to tolerate capping, and physicians placed greater emphasis on level of consciousness.

O'Connor et al ${ }^{29}$ examined the process of decannulation in patients transferred to a long-term acute care hospital. Decannulation was successful in $35 \%$ of patients at a median of $45 \mathrm{~d}$ following tracheostomy. Patients who failed decannulation had a tracheostomy tube placed earlier and had a shorter stay at the acute care referring hospital. At $3.5 \mathrm{y}, 35 \%$ of all patients and $62 \%$ of decannulated patients were alive.

\section{Accidental Decannulation}

Of concern from the perspective of patient safety is accidental decannulation. Accidental decannulation occurring in a patient with a mature stoma and with normal neck anatomy should be a benign event because the tracheostomy tube can usually be easily reinserted. The decision to permanently decannulate may be informed by an uncomplicated accidental decannulation. On the other hand, accidental decannulation may result in morbidity and mortality when it occurs in patients with a recently placed tracheostomy tube, substantial airway pathology, increased neck circumference, marginal oxygenation or in whom the tracheostomy tube is essential for mechanical ventilation. In these situations, airway patency must be quickly reestablished to avoid prolonged hypoxemia, organ failure, or death. ${ }^{30}$ An algorithm to manage unplanned decannulation is shown in Figure 13. ${ }^{26}$

White et $\mathrm{al}^{30}$ found an accidental decannulation rate of $\sim 4 / 1,000$ tracheostomy days in a long-term acute care hospital. Factors associated with accidental decannulation included mental status changes, increased secretions, and shift change. Several interventions were initiated with the intent to reduce the rate of accidental decannulation. These included increased availability of telemetry and oximetry and signage to identify patients at high risk of accidental 
decannulation. The result was a reduction in the rate of accidental decannulation to $2.7 / 1,000$ tracheostomy days.

\section{Tracheostomy Teams}

Tobin and Santamaria ${ }^{31}$ reported the impact of an intensivist-led multidisciplinary team to oversee ward management of patients with a tracheostomy. The team rounded twice each week. Bedside assessment was made of the patient's ability to tolerate cuff deflation, upper airway patency, speech, cough, and oxygen requirements. From this, an individualized plan for cuff deflation trials, use of speaking valves, and swallowing assessments was made. The team also ensured that humidifiers and suction were set up correctly and that spare tracheostomy tubes of the same size and smaller and tracheal dilators were at the bedside. Stay after ICU decreased over time, a higher proportion of decannulated patients were discharged, and the time to decannulation after ICU discharge decreased. In patients with traumatic brain injury, LeBlanc et $\mathrm{al}^{32}$ found that a tracheostomy team resulted in a significantly shorter stay and greater use of speaking valves. de Mestral et al ${ }^{33}$ reported their experience with the implementation of a tracheostomy team consisting of a surgeon, surgical resident, RT, speech-language pathologist, and clinical nurse specialist. There was a decreased incidence of tube blockage and calls for respiratory distress on the wards, a larger proportion of patients receiving speaking valves, and decreased time to first tube downsizing and to decannulation.

Speed and Harding ${ }^{34}$ conducted a systematic review and meta-analysis of 7 studies and found that the use of tracheostomy teams was associated with reductions in total tracheostomy time (4 studies, mean difference of $8 \mathrm{~d}$ ) and hospital stay ( 3 studies, mean difference of $14 \mathrm{~d}$ ). Reductions in ICU stay (3 studies) and increases in speaking valve use ( 3 studies) were also reported with tracheostomy teams.

\section{Ward Versus ICU}

There has been some concern raised about the safety of patients with a tracheostomy who are managed outside the ICU. Martinez et $\mathrm{al}^{35}$ reported that lack of decannulation of conscious tracheostomized patients before ICU discharge to the general ward was associated with higher mortality. Fernandez et $\mathrm{al}^{36}$ reported that lack of tracheostomy decannulation in the ICU was associated with ward mortality but only in patients with poor prognosis at the time of ICU discharge. In a prospective observational survey from 31 ICUs in Spain, Fernandez et al $^{37}$ reported that, after adjustment for the propensity score and Sabadell score, the presence of a tracheostomy cannula was not associated with any survival disadvantage. In an accompanying editorial, Schmidt et al ${ }^{38}$ recommended a decision tree for

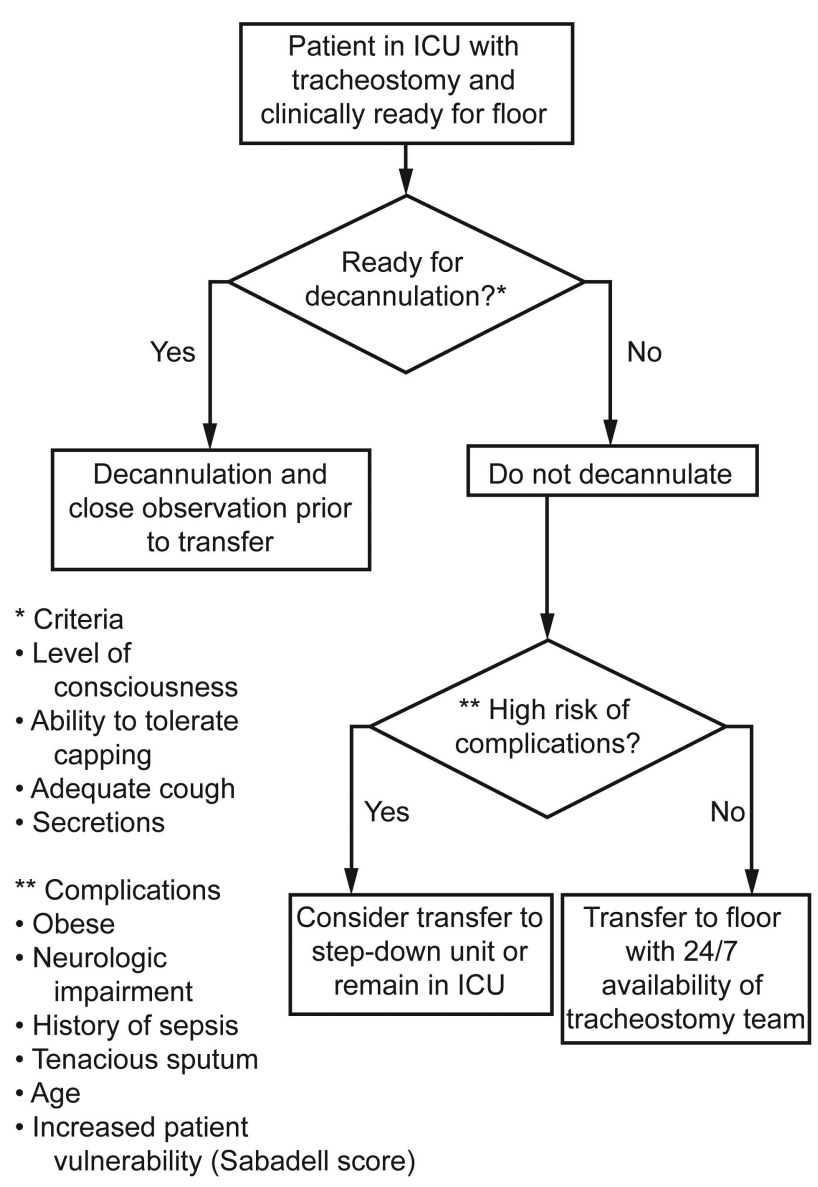

Fig. 14. Decision tree for decannulation and floor transfer of tracheostomized patients. From Reference 38 with permission.

decannulation and floor transfer of tracheostomized patients (Fig. 14).

\section{Speaking With a Tracheostomy Tube}

Placement of a tracheostomy decreases the ability of the patient to communicate effectively. It is possible to restore voice in many patients with a tracheostomy who are cognitively intact and free of laryngeal or pharyngeal dysfunction. The ability to speak provides an improvement in the quality of life for a patient with a tracheostomy. There are a variety of techniques to achieve this in patients with a tracheostomy who are breathing spontaneously or ventilator-dependent.

\section{Spontaneously Breathing Patients}

With the cuff deflated (or with a cuffless tube), patients (or their caregivers) can place a finger over the proximal opening of the tracheostomy tube to direct air through the upper airway and thus produce speech. Some patients are 


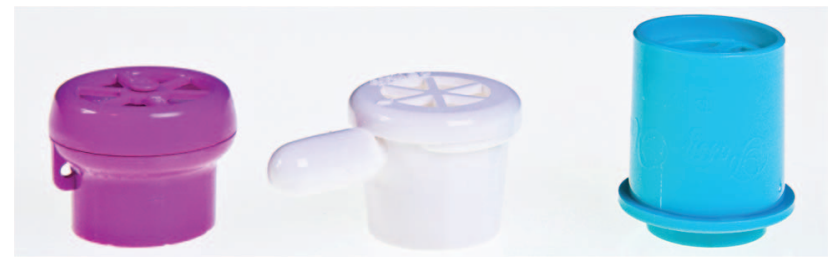

Fig. 15. Commercially available speaking valves.

Table 6. Speaking Valve Contraindications

Unconscious or comatose patients (relative)

Inflated tracheostomy tube cuff or foam-cuffed tracheostomy tube (absolute)

Thick and copious secretions (relative)

Severe upper airway obstruction (absolute)

Endotracheal tube rather than tracheostomy tube (absolute)

quite skilled with this technique, but many do not have the strength or coordination to master this method.

In the spontaneously breathing patient, a speaking valve (Fig. 15) directs the exhaled gas through the upper airway, which may allow the patient to speak. Although many patients can use this method effectively, there are several contraindications to the use of a speaking valve (Table 6). The speaking valve should be used only for a patient who is awake, responsive, and attempting to communicate. The patient must be able to exhale around the tracheostomy tube and through the upper airway, must be able to tolerate cuff deflation, and should be medically stable. Although the speaking valve might facilitate oral expectoration of secretions, airway clearance issues may occur if the patient has abundant secretions. The patient's risk for aspiration should be evaluated before the speaking valve is placed, and the advice of a speech-language pathologist can be valuable in this regard.

The patient must be able to exhale effectively around the tracheostomy tube when the speaking valve is placed. Tracheal pressure can be measured with the speaking valve in place (Fig. 16). If the tracheal pressure is $>5 \mathrm{~cm} \mathrm{H}_{2} \mathrm{O}$ during passive exhalation (without speech) with the speaking valve in place, this may indicate excessive expiratory resistance. ${ }^{2,39}$ If the tracheal pressure is high, consideration should be given to downsizing the tube. The upper airway should also be assessed for the presence of obstruction (eg, tumor, stenosis, granulation tissue, secretions). The cuff on a tracheostomy tube can create an obstruction, even when deflated, which might be improved with the use of an uncuffed tube or a tight-to-shaft cuff.

Before placing the speaking valve, the upper airway should be cleared of secretions, and the cuff must be completely deflated. A slow cuff deflation facilitates a smoother transition to flow through the upper airway. The lower respiratory tract may need to be suctioned after cuff de-

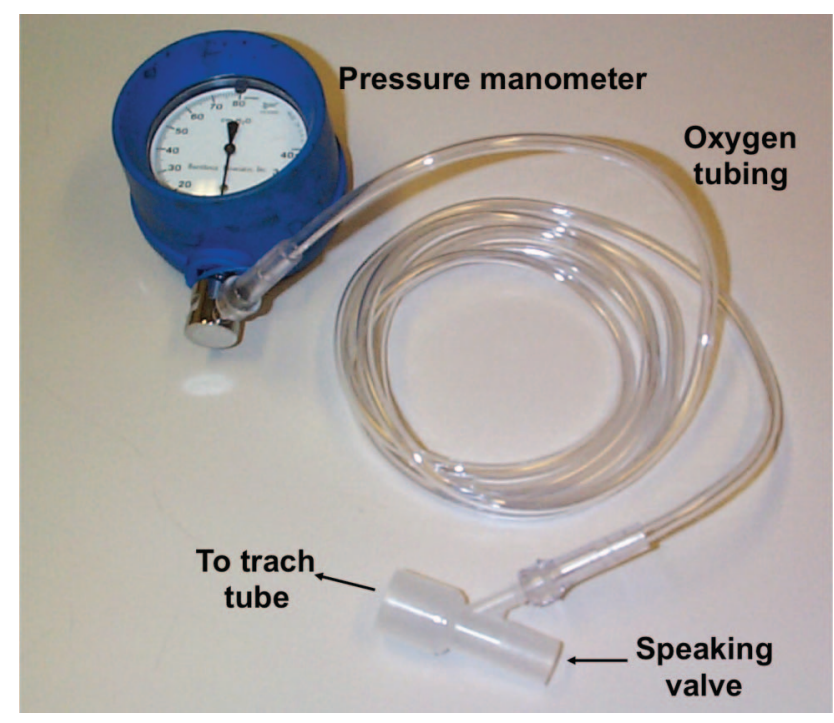

Fig. 16. Equipment used to measure tracheal pressure when a speaking valve is applied. From Reference 2.

flation due to aspiration of secretions from above the cuff. The ability of the patient to tolerate the speaking valve can be briefly assessed by finger occlusion of the tracheostomy tube after cuff deflation. Once the speaking valve is placed, the patient's ability to breathe should be carefully assessed. If the patient experiences difficulty with airway clearance when the speaking valve is in place, the valve should be removed to allow the patient to be suctioned. If the patient exhibits signs of respiratory distress, the speaking valve should be removed immediately, and upper airway patency should be reassessed.

Oxygen can be administered while the speaking valve is in place using a tracheostomy collar or an oxygen adapter on the speaking valve. The patient may inhale through the upper airway when the speaking valve is in place. This is most likely with a small tracheostomy tube, through which inspiratory resistance may be greater than that through the upper airway. When this occurs, oxygen administration to the upper airway may be required (eg, nasal cannula). Humidity can be applied using a tracheostomy collar, but a heat-and-moisture exchanger should not be used because the patient will not exhale through that device with the speaking valve in place. If inhaled aerosol medications are given, the speaking valve should be removed during this therapy.

Care must be taken to ensure that the cuff is deflated before the speaking valve is attached. A case was reported in which a speaking valve was mistaken for a heat-andmoisture exchanger; it was attached to a tracheostomy tube with the cuff inflated, and the result was pneumothorax and cardiac arrest. ${ }^{40}$

Prigent et $\mathrm{al}^{41}$ evaluated 6 commercially available speaking valves in a bench model and in 10 patients with a 


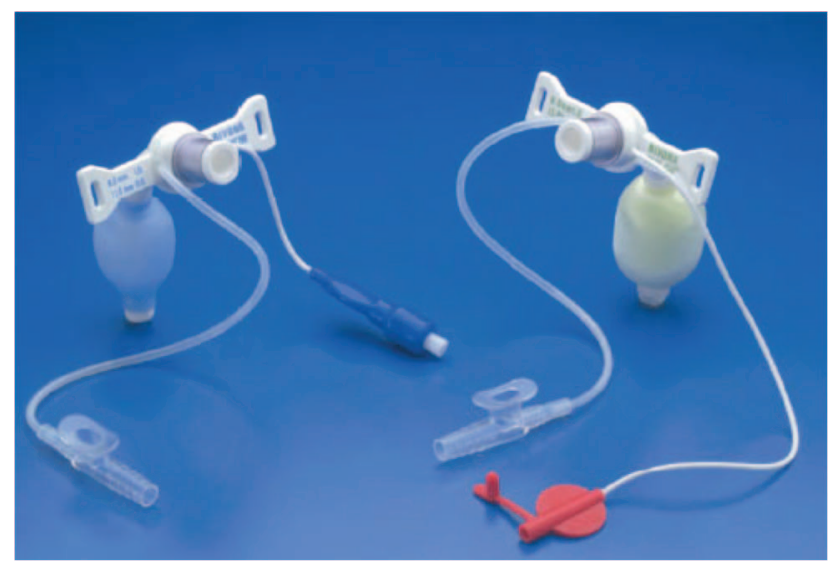

Fig. 17. Talking tracheostomy tubes. Courtesy Smiths Medical.

tracheostomy. There was a 4.4 ratio between the imposed work of breathing between the best and the worst valves. A significant effect on the Borg dyspnea score was observed between the best and the worst valves. These data suggest that device characteristics should be considered when selecting a speaking valve for clinical use.

Prigent et $\mathrm{al}^{42}$ investigated the effect of a speaking valve on breathing-swallowing interactions in 8 subjects with a tracheostomy who were able to breathe spontaneously. Chin electromyography, cervical piezoelectric sensor, and nasal and tracheal flow recordings were made, and 3 water-bolus sizes $(5,10$, and $15 \mathrm{~mL})$ were tested in random order. They found that swallowing characteristics and breathing-swallowing synchronization were not influenced by use of a speaking valve. However, expiratory flow toward the upper airway after swallowing was negligible without the speaking valve and was restored by adding the speaking valve. This might be important to decrease the risk of aspiration or laryngeal penetration.

Because the patient inhales through the tracheostomy tube (in addition to inhalation through the upper airway) and exhales through the upper airway, rebreathing (dead space) may be reduced, but this has not been studied. The use of a speaking valve might also allow the patient to control exhalation (eg, pursed lips in the patient with COPD), but this also has not been adequately studied. Improvements in olfaction have been reported with the use of a speaking valve..$^{43,44}$

\section{Mechanically Ventilated Patients}

The talking tracheostomy tube (Fig. 17) was designed to assist the patient to speak in a low whispered voice. ${ }^{2} \mathrm{~A}$ gas line with a thumb port is connected to a gas flow of 4-6 L/min. When the patient or caregiver occludes the thumb port, gas passes through the larynx, allowing the patient to speak in a soft whisper. Because the talking
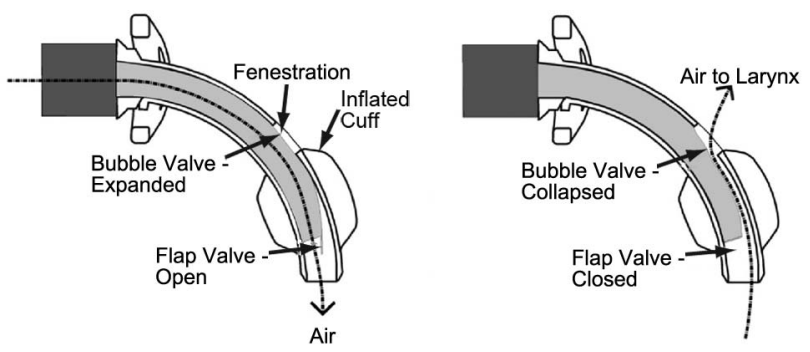

Fig. 18. Blom speech cannula. Inspiratory pressure opens the flap valve and closes (expands) the bubble valve, sealing the fenestration so that all of the tidal volume goes to the lungs. As inspiration ends, the flap valve closes. Expiratory pressure collapses the bubble valve, which unblocks the fenestration and directs all of the exhaled air to the upper airway to allow phonation. From Reference 45.

tracheostomy tube allows the use of voice with the cuff inflated, it decouples speech and breathing. Unless this tube is inserted at the time of the tracheostomy procedure, the use of this tube requires a tube change. In many cases, the voice quality is not good, a whisper at best. If the resistance to air flow above the stoma is less than that through the upper airway, much of the added flow may leak from the stomal site and not be available for speech. Upper airway secretions can interfere with voice quality, and secretions above the cuff can lead to a clogged gas flow line. Several days of use may be necessary before the patient is able to develop voice with this device. Even with practice and training, some patients cannot develop adequate voice with this device.

The Blom fenestrated tracheostomy tube (Fig. 6) has a speech cannula that is made of silicone and has 2 valves. Inspiratory pressure opens the flap valve and closes the bubble valve, sealing the fenestration so that all of the inspiratory air goes to the lungs. As inspiration ends, the flap valve closes. Expiratory pressure collapses the bubble valve, which unblocks the fenestration and directs all of the exhaled air to the upper airway to allow phonation (Fig. 18). The exhaled volume reservoir is a separate component that assists in preventing false low expiratory volume alarms that would occur because the exhaled breath is directed through the upper airway instead of back to the ventilator. The exhaled volume reservoir is a small silicone bellows system that expands and traps gas during inspiration and then returns the gas to the ventilator to be measured as exhaled volume during exhalation. In 10 mechanically ventilated patients with a tracheostomy, Kunduk et $\mathrm{al}^{45}$ found that the Blom speech cannula was safe, effective, and well tolerated while maintaining full cuff inflation.

When using a speaking valve with the cuff deflated or with a cuffless tube, gas flows from the ventilator into the tracheostomy tube during inhalation but exits through the upper airway during exhalation (Fig. 19). ${ }^{46}$ In other words, 
A
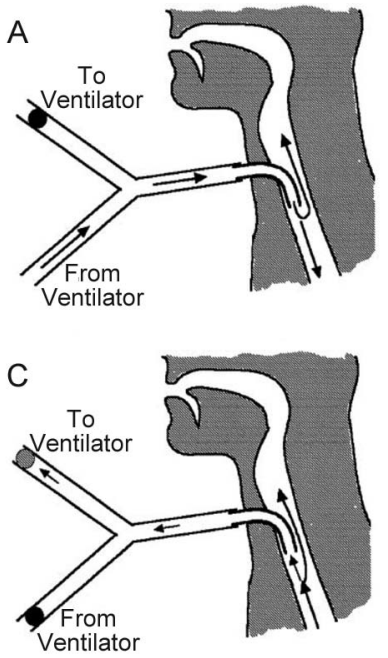
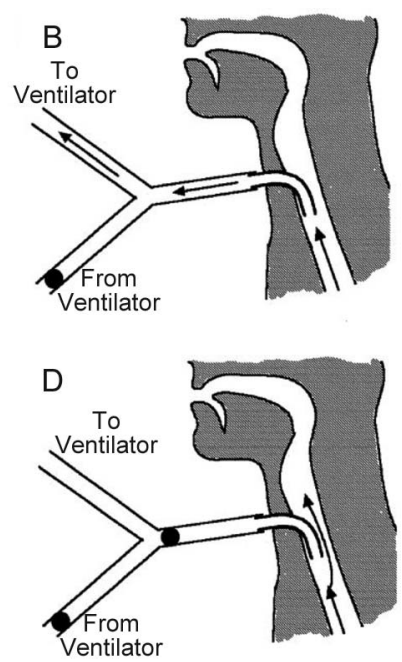

Fig. 19. Air flow during ventilator-supported speech production. The black circles represent occlusions, and the gray circle represents higher than usual impedance. A: During inspiration, air flows both toward the lungs and through the larynx. B: During usual expiration, almost all air flows toward the ventilator. This is because the impedance of the ventilator pathway is much lower than that of the laryngeal pathway during speech production. C: During expiration with PEEP, the impedance of the ventilator pathway is higher than usual, so more air flows through the larynx. D: During expiration with a one-way valve, all air flows through the larynx. From Reference 46 with permission.

the speaking valve is a one-way valve designed to attach to the proximal opening of the tracheostomy tube. Before placing the speaking valve, the cuff must be completely deflated. It may be necessary to increase the tidal volume delivery from the ventilator to compensate for volume loss through the upper airway during the inspiratory phase. Some patients are able to control oropharyngeal muscle tone sufficiently to minimize the leak through the upper airway during the inspiratory phase.

The alarms on most critical care ventilators are intolerant of a speaking valve. This can be addressed by using a ventilator with a speaking valve mode or a portable home care ventilator. Heated humidifiers can be used with a speaking valve. However, a heat-and-moisture exchanger should not be used because no exhaled gas passes through it if a speaking valve is in place. If an in-line closed suctioning system is used, the speaking valve should be connected to the side port to allow the catheter to easily pass into the tracheostomy tube. The volume of dead space in the ventilator circuit is unimportant when a speaking valve is used because there is no potential for rebreathing in the circuit.

Adequate cuff deflation, tracheostomy tube size and position, and upper airway obstruction should be assessed if the patient is unable to exhale adequately through the upper airway. Some patients complain of discomfort due to flow through the upper airway when the speaking valve is in place. This can result in drying of the pharyngeal membranes, inability to ventilate adequately, and increased noise levels. This may be the result of decreased pharyngeal or laryngeal tone due to weakness or atrophy from lack of flow through the upper airway during prolonged mechanical ventilation. This can be addressed by slow cuff deflation over several minutes. Initial placement of the speaking valve may stimulate coughing, which may be the result of secretions pooled above the cuff. This can be minimized by clearance of pharyngeal and tracheal secretions before the cuff is deflated. Some patients can communicate during both the inspiratory and expiratory phases of the ventilator. This is only problematic if it results in inadequate ventilation during speech. A speech-language pathologist can help patients who have difficulty adjusting to the speaking valve.

Passy et $\mathrm{al}^{47}$ reported their experience in a series of 15 ventilator-dependent patients in whom a speaking valve was used. In all 15 patients, there was an improvement in speech intelligibility, speech flow, elimination of speech hesitancy, and speech time. Manzano et $\mathrm{al}^{48}$ reported that a speaking valve was effective in improving communication in 8 of 10 chronic ventilator-dependent patients. In one patient, a speaking valve could not be used because adequate ventilation was not possible with the cuff deflated. In a second patient, the speaking valve was not effective due to laryngopharyngeal dysfunction.

The work of Hoit and colleagues ${ }^{46,48-51}$ and Prigent and colleagues $^{52-54}$ has informed clinicians on techniques to facilitate speech without the use of a speaking valve. They have shown that simple manipulations on the ventilator allow the patient to speak during both the inspiratory and expiratory phases. Moreover, the lack of a speaking valve may increase safety should the upper airway become obstructed.

If the cuff is deflated, gas can escape through the upper airway during the inspiratory phase (Fig. 19). This leak results in ability to speak during the inspiratory phase. It has been shown that increasing the inspiratory time setting on the ventilator increases speaking rate (syllables/min). ${ }^{46,53,54}$ If the PEEP setting on the ventilator is zero, most of the exhaled gas exits through the ventilator circuit rather than the upper airway. In this situation, there is little ability to speak during the expiratory phase. If PEEP is set on the ventilator, then expiratory flow is more likely to occur through the upper airway, which increases speaking rate.

The use of a longer inspiratory time and higher PEEP are additive in their ability to improve speaking rate. ${ }^{46}$ Tracheal pressure (important for speech) is similar with the use of PEEP and the use of a speaking valve. By prolonging the inspiratory time and using PEEP, mechanically ventilated patients with a tracheostomy may be able to use $60-80 \%$ of the breathing cycle for speaking. Some 


\section{Tracheostomy Tubes}

patients are able to speak throughout the entire ventilatory cycle without any pauses for breathing. This is unlike normal subjects without a tracheostomy tube, who speak only during the expiratory phase.

The ventilator is normally flow-cycled during pressure support ventilation. In the presence of a leak through the upper airway, the ventilator may fail to cycle appropriately and thus result in a prolonged inspiratory phase. Although this would usually be considered undesirable, it might facilitate speech. Prigent et $\mathrm{al}^{54}$ reported that pressure support with PEEP and the cuff deflated resulted in an increase in inspiratory time during speech, and this improved speech duration during both the inspiratory and expiratory phases. This occurred with minimal effect on gas exchange parameters.

Prigent et al ${ }^{53}$ found that text reading time, perceptive score, intelligibility score, speech comfort, and respiratory comfort were similar with PEEP and with a speaking valve. During speech with PEEP at $5 \mathrm{~cm} \mathrm{H}_{2} \mathrm{O}, 6$ of the 10 patients had no return of expiratory gas to the expiratory line and therefore had the entire tidal volume available for speech. During speech, the breathing frequency increased by at least 3 breaths/min above the backup rate in 7 of the 10 patients with PEEP and in none of the patients with a speaking valve.

\section{Summary}

Tracheostomy tubes are available in a variety of sizes and styles. It is important for RTs, physicians, speechlanguage pathologists, nurses, and others caring for patients with a tracheostomy tube to understand these differences and select a tube that appropriately fits the patient. The ability to speak is an important aspect of the quality of life for patients with a tracheostomy. A variety of techniques to achieve this are available for either mechanically ventilated or spontaneously breathing patients.

\section{REFERENCES}

1. Hess DR. Tracheostomy tubes and related appliances. Respir Care 2005;50(4):497-510.

2. Hess DR. Facilitating speech in the patient with a tracheostomy. Respir Care 2005;50(4):519-525.

3. Mallick A, Bodenham A, Elliot S, Oram J. An investigation into the length of standard tracheostomy tubes in critical care patients. Anaesthesia 2008;63(3):302-306.

4. White AC, Kher S, O'Connor HH. When to change a tracheostomy tube. Respir Care 2010;55(8):1069-1075.

5. Rumbak MJ, Walsh FW, Anderson WM, Rolfe MW, Solomon DA. Significant tracheal obstruction causing failure to wean in patients requiring prolonged mechanical ventilation: a forgotten complication of long-term mechanical ventilation. Chest 1999;115(4):1092-1095.

6. Tibballs J, Robertson C, Wall R. Tracheal ulceration and obstruction associated with flexible Bivona tracheostomy tubes. Anaesth Intensive Care 2006;34(4):495-497.
7. Schmidt U, Hess D, Kwo J, Lagambina S, Gettings E, Khandwala F, et al. Tracheostomy tube malposition in patients admitted to a respiratory acute care unit following prolonged ventilation. Chest 2008; 134(2):288-294.

8. Burns SM, Spilman S, Wilmoth D, Carpender R, Turrentine B, Wiley B, Marshall M, Marten S, Burns JE, Truwit JD. Are frequent inner cannula changes necessary? A pilot study. Heart Lung 1998; 27(1):58-62.

9. Cowan T, Op't Holt TB, Gegenheimer C, Izenberg S, Kulkarni P. Effect of inner cannula removal on the work of breathing imposed by tracheostomy tubes: a bench study. Respir Care 2001;46(5):460-465.

10. Siddharth P, Mazzarella L. Granuloma associated with fenestrated tracheostomy tubes. Am J Surg 1985;150(2):279-280.

11. Hussey JD, Bishop MJ. Pressures required to move gas through the native airway in the presence of a fenestrated vs a nonfenestrated tracheostomy tube. Chest 1996;110(2):494-497.

12. Carter A, Fletcher SJ, Tuffin R. The effect of inner tube placement on resistance and work of breathing through tracheostomy tubes: a bench test. Anaesthesia 2013;68(3):276-282.

13. Muscedere J, Rewa O, McKechnie K, Jiang X, Laporta D, Heyland DK. Subglottic secretion drainage for the prevention of ventilatorassociated pneumonia: a systematic review and meta-analysis. Crit Care Med 2011;39(8):1985-1991.

14. Amathieu R, Sauvat S, Reynaud P, Slavov V, Luis D, Dinca A, et al. Influence of the cuff pressure on the swallowing reflex in tracheostomized intensive care unit patients. Br J Anaesth 2012;109(4):578583.

15. McCracken J, Leasa D. Trach tubes designed to maximize safety may increase risk to ventilated patients. Crit Care 2010;14(6):1008.

16. Beard B, Monaco MJ. Tracheostomy discontinuation: impact of tube selection on resistance during tube occlusion. Respir Care 1993; 38(3):267-270.

17. Hernandez G, Pedrosa A, Ortiz R, Cruz Accuaroni Mdel M, Cuena $\mathrm{R}$, Vaquero Collado $\mathrm{C}$, et al. The effects of increasing effective airway diameter on weaning from mechanical ventilation in tracheostomized patients: a randomized controlled trial. Intensive Care Med 2013;39(6):1063-1070.

18. Brown JM, White MC. Conversion from suction catheter to guidewire for difficult tracheostomy tube change. Anaesth Intensive Care 2004;32(6):842.

19. Fisher DF, Kondili D, Williams J, Hess DR, Bittner EA, Schmidt UH. Tracheostomy tube change before day 7 is associated with earlier use of speaking valve and earlier oral intake. Respir Care 2013;58(2):257-263.

20. Tabaee A, Lando T, Rickert S, Stewart MG, Kuhel WI. Practice patterns, safety, and rationale for tracheostomy tube changes: a survey of otolaryngology training programs. Laryngoscope 2007;117(4): 573-576.

21. Yaremchuk K. Regular tracheostomy tube changes to prevent formation of granulation tissue. Laryngoscope 2003;113(1):1-10.

22. Björling G, Axelsson S, Johansson UB, Lysdahl M, Markström A, Schedin U, et al. Clinical use and material wear of polymeric tracheostomy tubes. Laryngoscope 2007;117(9):1552-1559.

23. Backman S, Björling G, Johansson UB, Lysdahl M, Markström A, Schedin U, et al. Material wear of polymeric tracheostomy tubes: a six-month study. Laryngoscope 2009;119(4):657-664.

24. Heffner JE. The technique of weaning from tracheostomy. Criteria for weaning; practical measures to prevent failure. J Crit Illn 1995; 10(10):729-733.

25. Christopher KL. Tracheostomy decannulation. Respir Care 2005; 50(4):538-541.

26. O'Connor HH, White AC. Tracheostomy decannulation. Respir Care 2010;55(8):1076-1081. 


\section{Tracheostomy Tubes}

27. Stelfox HT, Crimi C, Berra L, Noto A, Schmidt U, Bigatello LM, Hess D. Determinants of tracheostomy decannulation: an international survey. Crit Care 2008;12(1):R26.

28. Stelfox HT, Hess DR, Schmidt UH. A North American survey of respiratory therapist and physician tracheostomy decannulation practices. Respir Care 2009;54(12):1658-1664.

29. O'Connor HH, Kirby KJ, Terrin N, Hill NS, White AC. Decannulation following tracheostomy for prolonged mechanical ventilation. J Intensive Care Med 2009;24(3):187-194.

30. White AC, Purcell E, Urquhart MB, Joseph B, O'Connor HH. Accidental decannulation following placement of a tracheostomy tube. Respir Care 2012;57(12):2019-2025.

31. Tobin AE, Santamaria JD. An intensivist-led tracheostomy review team is associated with shorter decannulation time and length of stay: a prospective cohort study. Crit Care 2008;12(2):R48.

32. LeBlanc J, Shultz JR, Seresova A, de Guise E, Lamoureux J, Fong N, et al. Outcome in tracheostomized patients with severe traumatic brain injury following implementation of a specialized multidisciplinary tracheostomy team. J Head Trauma Rehabil 2010;25(5):362-365.

33. de Mestral C, Iqbal S, Fong N, LeBlanc J, Fata P, Razek T, Khwaja $\mathrm{K}$. Impact of a specialized multidisciplinary tracheostomy team on tracheostomy care in critically ill patients. Can J Surg 2011;54(3): 167-172.

34. Speed L, Harding KE. Tracheostomy teams reduce total tracheostomy time and increase speaking valve use: a systematic review and meta-analysis. J Crit Care 2013;28(2):216.e1-216.e10.

35. Martinez GH, Fernandez R, Casado MS, Cuena R, Lopez-Reina P, Zamora S, Luzon E. Tracheostomy tube in place at intensive care unit discharge is associated with increased ward mortality. Respir Care 2009;54(12):1644-1652.

36. Fernandez R, Bacelar N, Hernandez G, Tubau I, Baigorri F, Gili G, Artigas A. Ward mortality in patients discharged from the ICU with tracheostomy may depend on patient's vulnerability. Intensive Care Med 2008;34(10):1878-1882.

37. Fernandez R, Tizon AI, Gonzalez J, Monedero P, Garcia-Sanchez M, de-la-Torre MV, et al. Intensive care unit discharge to the ward with a tracheostomy cannula as a risk factor for mortality: a prospective, multicenter propensity analysis. Crit Care Med 2011;39(10):2240-2245.

38. Schmidt U, Hess D, Bittner E. To decannulate or not to decannulate: a combination of readiness for the floor and floor readiness? Crit Care Med 2011;39(10):2360-2361.

39. Johnson DC, Campbell SL, Rabkin JD. Tracheostomy tube manometry: evaluation of speaking valves, capping and need for downsizing. Clin Respir J 2009;3(1):8-14.

40. Selleng S, Antal M, Hansen T, Meissner K, Usichenko TI. Pneumothorax and cardiac arrest caused by speaking valve mistaken as moisture exchanger: an incident report. Br J Anaesth 2013;111(2):297298.
41. Prigent H, Orlikowski D, Blumen MB, Leroux K, Legrand L, Lejaille $\mathrm{M}$, et al. Characteristics of tracheostomy phonation valves. Eur Respir J 2006;27(5):992-996.

42. Prigent H, Lejaille M, Terzi N, Annane D, Figere M, Orlikowski D, Lofaso F. Effect of a tracheostomy speaking valve on breathingswallowing interaction. Intensive Care Med 2012;38(1):85-90.

43. Shikani AH, Dietrich-Burns K. Comparison of speech parameters and olfaction using different tracheotomy speaking valves. Int Forum Allergy Rhinol 2012;2(4):348-353.

44. Lichtman SW, Birnbaum IL, Sanfilippo MR, Pellicone JT, Damon WJ, King ML. Effect of a tracheostomy speaking valve on secretions, arterial oxygenation, and olfaction: a quantitative evaluation. J Speech Hear Res 1995;38(3):549-555.

45. Kunduk M, Appel K, Tunc M, Alanoglu Z, Alkis N, Dursun G, Ozgursoy OB. Preliminary report of laryngeal phonation during mechanical ventilation via a new cuffed tracheostomy tube. Respir Care 2010;55(12):1661-1670.

46. Hoit JD, Banzett RB, Lohmeier HL, Hixon TJ, Brown R. Clinical ventilator adjustments that improve speech. Chest 2003;124(4):15121521.

47. Passy V, Baydur A, Prentice W, Darnell-Neal R. Passy-Muir tracheostomy speaking valve on ventilator-dependent patients. Laryngoscope 1993;103(6):653-658.

48. Manzano JL, Lubillo S, Henríquez D, Martín JC, Pérez MC, Wilson DJ. Verbal communication of ventilator-dependent patients. Crit Care Med 1993;21(4):512-517.

49. Hoit JD, Lohmeier HL. Influence of continuous speaking on ventilation. J Speech Lang Hear Res 2000;43(5):1240-1251.

50. Hoit JD, Shea SA, Banzett RB. Speech production during mechanical ventilation in tracheostomized individuals. J Speech Hear Res 1994;37(1):53-63.

51. Shea SA, Hoit JD, Banzett RB. Competition between gas exchange and speech production in ventilated subjects. Biol Psychol 1998; 49(1-2):9-27.

52. Garguilo M, Leroux K, Lejaille M, Pascal S, Orlikowski D, Lofaso F, Prigent H. Patient-controlled positive end-expiratory pressure with neuromuscular disease: effect on speech in patients with tracheostomy and mechanical ventilation support. Chest 2013;143(5):12431251.

53. Prigent H, Garguilo M, Pascal S, Pouplin S, Bouteille J, Lejaille M, et al. Speech effects of a speaking valve versus external PEEP in tracheostomized ventilator-dependent neuromuscular patients. Intensive Care Med 2010;36(10):1681-1687.

54. Prigent H, Samuel C, Louis B, Abinun MF, Zerah-Lancner F, Lejaille $\mathrm{M}$, et al. Comparative effects of two ventilatory modes on speech in tracheostomized patients with neuromuscular disease. Am J Respir Crit Care Med 2003;167(2):114-119.

\section{Discussion}

Napolitano: Dean, a controversy at our institution between the ENT [otolaryngology] surgeons and the general surgeons who also place trachs is, at the time that a patient is ready to go to an uncuffed tube, whether we should use a stainless steel Jackson or an uncuffed anything else. We have Shileys at our institution, so we commonly use an uncuffed Shiley. Our ENT surgeons commonly propose that the stainless steel Jackson tubes are the best at reducing granulation tissue and reaction in the airway. The difficulty we have is if that patient, at some point, requires any kind of positive pressure or a little bit of bag assistance, where the adapter to the tracheostomy tube is problematic.
Hess: Correct. We end up with all sorts of jerry-rigged adapters at the bedside. I had a slide about metal trach tubes that I took out because I thought nobody uses them anymore. Are they commercially available?

Napolitano: They are still available. They are reusable tracheostomy tubes, and they actually go back to the OR 
[operating room] and get sterilized for future additional use. They come in a sterile autoclave package.

Hess: We have some that have been recycled numerous times. I just didn't know we could get new ones. Our practice is similar to yours. If we go to an uncuffed trach tube, we use a Shiley or a Portex uncuffed with the standard 15-mm connector. If we are concerned that the patient might have to go back on the ventilator, we consider a tightto-shaft cuff.

Napolitano: Another challenge we have is our tracheal stoma patients. Those patients who are not ventilated are fine since they have a large tracheal stoma, but when they need mechanical ventilation, finding the proper trach size, placement, and the correct balloon that doesn't require too much pressure to keep it within the airway. Any tips and tricks regarding optimal tracheostomy tubes for patients with a chronic tracheostomy stoma?

Hess: Generally, what we've done is use a size 6 Shiley or something like that. It generally takes a smaller tube, and other than that, I don't think we've done anything out of the ordinary.

Durbin: One problem with this approach is the length of the cuff and the fact that the permanent stoma is generally closer to the carina than a typical temporary tracheostomy stoma. Even with a smaller tube, you've got a long cuff in the stoma, which may be at or in the bronchus after placement. There's an ETT [endotracheal tube] called an MLT [microlaryngeal tracheal] tube, which has a very short cuff. These tubes also come in various sizes, including very small diameters, but are the same length as traditional ETTs. You can cut and shorten the length of an MLT tube to take advantage of the shorter cuff. Another tube that can be used in a stoma is the wirewrapped or armored tube. These have a slightly shorter cuff, are very flexi- ble, impossible to kink, but cannot be cut to shorten them. Another disadvantage is they also include a highpressure cuff, which is not desirable for long term use.

Hess: So, you're saying you could use one of the adjustable flange Bivona tubes, for example.

Durbin: I've not used tracheostomy tubes in permanent stomas. I've used the traditional ETTs because they are flexible, conform to the tracheal anatomy, and have short cuffs, at least in the two I mentioned. I'm more familiar with their cuff sizes, and there are a variety of different sizes available to choose from without special ordering. The armored tube, at least from some manufacturers, does have a higher pressure cuff; that's one downside of using it.

Hess: But we're usually talking short-term here.

\section{Durbin: Yes.}

Napolitano: Or somebody gets pneumonia after having had surgery and then develops respiratory failure and requires mechanical ventilation. Again, it's the issue that, if you put a regular size trach in, the tip might be in the right main bronchus. The regular sizes are usually too long because the tracheal stoma is farther down on the trachea.

Hess: But using a smaller diameter tube is also a shorter tube, and that's an issue we see sometimes as we're downsizing trach tubes. The tube gets downsized to make more room around the tube so that the patient can use the upper airway, and then the tube is butting against the posterior tracheal wall because it's a short tube.

Durbin: To answer your previous question on metal tubes, I just did a computer search. For $\$ 85-\$ 100$ each, you can get stainless steel metal tra- cheostomy tubes delivered tomorrow from Amazon.com.

Hess: I guess I will put something about metal trach tubes into the paper.

Napolitano: Dean, one other question. In your team approach for downsizing and decannulation, do you have tips regarding whether it's logical or not logical to do an endoscopy and really evaluate the glottis before you consider tracheostomy downsizing or decannulation?

Hess: We do not do that regularly. The thing that RTs [respiratory therapists] will do is to use a manometer and measure the tracheal pressures. If the cuff is down and the expiratory pressures are $>10 \mathrm{~cm} \mathrm{H}_{2} \mathrm{O}$, then the first thing we would likely do is downsize the trach tube. If we downsize the trach tube and we're still getting high pressures and the patient is not tolerating the speaking valve or the cap, the next step would be to do the endoscopy to look at the upper airway pathology.

Hurford: What happens frequently is a surgeon puts in a tracheostomy, the patient comes back to the ICU, you measure the cuff pressure when they're returning from the OR with a fresh tracheostomy, and it's $50 \mathrm{~cm} \mathrm{H}_{2} \mathrm{O}$. What is your approach to a patient with a fresh tracheostomy and a high cuff pressure?

Hess: First of all, to make sure it really needs to be $50 \mathrm{~cm} \mathrm{H}_{2} \mathrm{O}$. Sometimes, it's 50; we lower it to 25 , and it's okay. But you're assuming we lower it to 25 and it leaks, so then what do we do? We could try to reposition the tube, or we get the surgeon involved because that may require an upsize of the trach tube. It's a fresh trach, I would have the surgeon there. Lena, I'll defer to you as the surgeon in the group. What would you do? 
Napolitano: I would say we'd go to the bedside first to troubleshoot and figure out whether we put the wrong size trach in or whether it is not large or long enough. But I think we would also look carefully at the ventilator settings as well. We' re ventilating with low pressures: could we do anything to modify and lower the $\mathrm{V}_{\mathrm{T}}$ [tidal volume]?

Hess: Let's assume we're on $6 \mathrm{~mL} / \mathrm{kg}$ and $10 \mathrm{~cm} \mathrm{H}_{2} \mathrm{O}$ PEEP.

Napolitano: Yes, if you need to change it out, you need to change it out. Again, we do both our open and percutaneous tracheostomies bedside and in the ICU, so the patient doesn't need to go anywhere to further evaluate all issues.

Hess: Right, so you'd know right away.

Hurford: Sometimes, the cause of high cuff pressure seems to be a problem of fit, where the cuff is sitting eccentrically in the trachea. I guess the question is how do you know whether you need a long proximal limb or a long distal limb? How do you react to the patient with severe tracheomalacia who may need a large volume of air in the cuff?

Hess: Sometimes, it's positional, as you point out, and you can try to reposition the trach tube. But if the issue is that the tube is not positioned well in the trachea, maybe it needs to be a longer tube, maybe there is tracheal pathology. I think then you need to put a bronchoscope in and take a look. In the patient series we reported, ${ }^{1}$ the way that trach tube malpositions were identified was bronchoscopy.

Ramachandran: Can I explore the concept of your trach team a little more? If you need a trach tube change before the 5-d mark, where you said you're reasonably comfortable doing it at the bedside, how do you do that? In everybody, first, and then in somebody with a difficult airway?

Hess: The approach is we have a group of RTs who are our trach team therapists; an RT sees these patients every $4 \mathrm{~h}$ around the clock. The trach team therapists are really good at doing trach tube changes and the other technical aspects of trach care; they're also really good in their clinical judgment and know when they shouldn't try to do this by themselves. So, if it's the second or third day after the trach tube placement and the tube needs to be changed, we call the surgeon back. We don't mess with that. It becomes something that the surgical team takes care of: that's the MD on the team. The first trach tube change is always done with somebody from the service that placed the trach tube present. If, in their judgment, they could get into trouble, they will ask for a more senior resident or attending physician to be present. After the first trach tube change, the therapists do the tube changes, and the only requirement is that there is a physician nearby. The therapists on the trach team have a lot of technical expertise, but more important is their excellent judgment and knowing when to get help.

Ramachandran: There's some evidence in the anesthesia literature that the use of fluids in cuffs causes less postoperative sore throat and less irritation to the tracheal mucosa. Any evidence of that in the ICU population?

Hess: I don't know if that's been studied. We inflate the cuffs with air unless it's the tight-to-shaft cuff. One of the issues with fluid inflation of the cuff is how would you know how much pressure the cuff is exerting against the tracheal wall? I'm not sure how we'd measure the cuff pressure.

Ramachandran: Apparently, it's less than the air pressure.

Hess: Okay, does anybody know anything about that? I haven't seen anything in the literature.

Branson: This is a common practice at altitude; a lot of places fill cuffs with saline.

Hess: And in the hyperbaric chamber.

Branson: Right. We've measured pressures when they're filled with saline, and the pressures are actually quite high.

Hess: Interesting. Sounds like a great research question.

\section{REFERENCES}

1. Schmidt U, Hess D, Kwo J, Lagambina S, Gettings E, Khandwala F, et al. Tracheostomy tube malposition in patients admitted to a respiratory acute care unit following prolonged ventilation. Chest 2008;134(2): 288-294. 